\title{
The long-run determinants of fertility: one century of demographic change 1900-1999
}

\author{
Dierk Herzer • Holger Strulik • Sebastian Vollmer
}

Published online: 10 October 2012

(C) The Author(s) 2012. This article is published with open access at Springerlink.com

\begin{abstract}
We examine the long-run relationship between fertility, mortality, and income using panel cointegration techniques and the available data for the last century. Our main result is that mortality changes and growth of income contributed to the fertility transition. The fertility reduction triggered by falling mortality, however, is not enough to overcompensate the positive effect of falling mortality on population growth. This means that growth of income per capita is essential to explain the observed secular decline of population growth. These results are robust to alternative estimation methods, potential outliers, sample selection, different measures of mortality, the sample period, the inclusion of education as an explanatory variable, and the use of different data sets. In addition, our causality tests suggest that fertility changes are both cause and consequence of economic development.
\end{abstract}

Keywords Fertility $\cdot$ Mortality $\cdot$ Economic development $\cdot$ Panel cointegration

JEL Classification $\quad \mathrm{J} 1 \cdot \mathrm{J} 13 \cdot \mathrm{C} 23$

\section{Introduction}

Every successfully developing country runs through two transformations, an industrial revolution, characterized by a secular take-off of income per capita, and a demographic transition,

\footnotetext{
D. Herzer

Department of Economics, Helmut-Schmidt-University Hamburg, Holstenhofweg 85, 22043 Hamburg, Germany e-mail: herzer@hsu-hh.de

H. Strulik $(\varangle) \cdot S$. Vollmer

Department of Economics, University of Göttingen, Platz der Göttinger Sieben 3, 37073 Göttingen, Germany

e-mail: holger.strulik@wiwi.uni-goettingen.de

S. Vollmer

Department of Global Health and Population, Harvard School of Public Health, Boston, MA, USA e-mail: svollmer@uni-goettingen.de; svollmer@hsph.harvard.edu
} 
characterized by decreasing mortality and fertility rates. Although there are also important issues of timing the most salient observation is the close chronological proximity of both transformations suggesting that they are causally related.

The most debated question in this respect is probably whether the fertility decline is mainly caused by declining mortality - this would be the typical demographer's view-or whether declining fertility is essentially caused by technological change and the associated secular rise of income per capita and the demand for human capital-the typical economist's view. Moreover, unified growth theory argues that fertility changes are both cause and consequence of economic development (Galor 2005).

The objectives of this paper are to examine the long-run effects of mortality and income on fertility and to disentangle the intricate problems of causality. Specifically, we make two main contributions: first, we apply panel cointegration techniques to data for the period from 1900 to 1999 . Panel cointegration estimators are robust under cointegration to a variety of estimation problems that often plague empirical work, including omitted variables and endogeneity (see, e.g., Banerjee 1999; Baltagi and Kao 2000; Pedroni 2007).

The greatest advantage of cointegration techniques is perhaps the invariance of the cointegration property to an extension of the information set (Lütkepohl 2007). This justifies the focus on a small "subsystem" that neglects other potential drivers of economic growth and the demographic transition. In other words, if we find that fertility, mortality, and the log of income are cointegrated, the found relationship between these variables is robust against the inclusion of further variables that are thought to be relevant for demo-economic development as well. We demonstrate this property below by adding a further important variable of the fertility transition, education. This means that, although we cannot include education right from the beginning because of data limitations, the cointegration property ensures that we can rigorously analyze the income and mortality channel of fertility without considering jointly education and all other potential channels of the fertility transition.

Because the demographic transition is an inherently dynamic phenomenon, the most interesting quest for causality is probably along the time-dimension. As a second contribution, we therefore examine if and to what extent an observable fertility change should be seen as a response to a preceding change of mortality or as a response to a preceding change of income. For this purpose we use Granger-causality tests and impulse response functions. These techniques appear to be the most appropriate tools because the idea of causality in the Granger sense is that the cause occurred before the effect. ${ }^{1}$

The remainder of the paper is composed of four sections. In Sect. 2, we discuss the theoretical background and the empirical evidence. Section 3 sets up the basic empirical model and describes the data. Section 4 presents the econometric implementation and our main results. It documents that economic growth as well as declining mortality explain large parts of the fertility decline observed during the last century, that declining mortality per se is insufficient to explain the secular decline of population growth, and that, in accordance with the main thesis of unified growth theory, fertility changes are both cause and consequence of successful economic development. Section 5 concludes. A detailed description of the data and of our econometric tests can be found in the Appendix.

\footnotetext{
1 Nevertheless it could be that Granger causality fails to identify true causality. It could be that the cointegrated variables are driven by another neglected process. This, however, would not affect the identified stationary relationship between the cointegrated variables.
} 


\section{Theoretical background and empirical evidence}

\subsection{Theory}

Most of the available theories of the demographic transition focus either on the impact of mortality or on the impact of income and economic growth on fertility. Demographers seem to emphasize the mortality channel while economists emphasize the role of economic development and the associated rise in the growth in income, the demand for human capital, and the decline in the gender wage gap.

Among the most prominent explanations for the mortality channel are physiological mechanisms (the link between breastfeeding and fecundity) and the concept of an ideal family size (implying the wish for replacement of deceased children). Inspired by the observation that in most countries-France is a prominent outlier-the mortality decline occurred before the fertility decline, many demographers argue in favor of a causal impact of mortality on fertility (Cleland 2001). The so far available econometric evidence, however, has been mixed. In a popular survey Kirk (1996) concludes: "It is perhaps surprising that while mortality decline is usually cited as the raison d' étre for fertility decline, it is not often accorded a primary place as a cause of fertility decline. This is understandable, since efforts to establish a direct close connection have had mixed results. Whilst definite proof of this connection may not be possible, there exists cogent reasons for supposing that it exists."

While conventional physiological channels can rationalize a negative association between fertility and mortality, they are certainly insufficient to explain the demographic transition understood as the secular decline of net fertility, i.e. of the number of surviving children per family and thus the secular decline of population growth. For that, economic theory has proposed several refinements of the theory. Most well-known is probably the idea of precautionary child-bearing of risk-averse parents (Sah 1991; Kalemli-Ozcan 2002). More complex theories involve the interaction between extrinsic survival conditions and child health (Strulik 2008) and the impact of adult longevity on fertility (Soares 2005; Cervellati and Sunde 2007).

Many economic theories of fertility, however, without explicitly denying a role of mortality, argue in favor of an independent, stand-alone impact of economic development on fertility. The main objective of the earlier literature was to explain a negative association between income and fertility without abandoning the assumption of children as "normal goods" (Becker 1965; Becker and Lewis 1973). With the rise of unified growth theory (Galor $2005,2011)$ the economic analysis of fertility has been reframed in a dynamic context. The focus shifted away from the association between fertility and income (across countries) towards the association between fertility change, income growth, and human capital formation (within countries over time). Moreover, the time-cost idea and the child quality-quantity trade off have been refined in several new ways. For example, it has been proposed that rising income-as a proxy for technological progress-is associated with a reduction of the comparative advantage of men in production and thus rises the opportunity cost of fertility for women (Galor and Weil 1996), that technological progress raises the importance of human capital (education, child quality) vis a vis raw labor in production since educated individuals have a comparative advantage in a changing technological environment (Galor and Weil 2000; Galor and Moav 2002), and that technological progress changes the structural composition of the economy toward manufacturing and thus raises the relative price of nutrition, i.e. the relative price of child quantity (Kögel and Prskawetz 2001; Strulik and Weisdorf 2008). ${ }^{2}$

2 Other channels that have been invoked in order to generate or amplify a negative impact of income or income growth on fertility are the old-age security hypothesis (Neher 1971; Strulik 2003) and child labor (see e.g. 
A common element of these theories is that-without further assumptions-mortality plays no role in explaining population growth. Indeed if child mortality is added in a standard fashion to these frameworks it cancels out in the computation of the optimal net rate of reproduction (i.e. net fertility, see Doepke 2005; Galor 2011). Without further augmentation these models thus predict that a change of mortality leads to a one-to-one response of fertility and has no consequences on population growth. An impact of mortality on fertility can be established by abandoning the assumption of homothetic utility. In an earlier discussion paper version of this article we have shown that a thus accommodated model predicts that net fertility is negatively associated with mortality, implying the prediction that declining mortality is not sufficient to explain the phenomenon of declining population growth during the demographic transition (Herzer et al. 2010; see also Strulik and Weisdorf 2012).

\subsection{Evidence}

There exists still surprisingly little macro-econometric evidence on the determinants of fertility in modern (i.e. post-Malthusian) times. ${ }^{3}$ Overall, the available literature provides a mixed and inconclusive picture. Across countries Brander and Dowrick (1994) document a negative association between fertility and economic growth, Schultz (1997) finds that income per adult is negatively associated with mortality and positively with fertility, and Ahituv (2001) finds a negative association between fertility and income per capita. Lorentzen et al. (2008) find a positive association between fertility and mortality and (indirectly) a negative association between fertility and economic growth. Without explicitly considering fertility, Acemoglu and Johnson (2007) observe a negative impact of life-expectancy on income per capita. Cervellati and Sunde (2011) demonstrate that this result depends heavily on the selected sample. In particular for countries that have already initiated the fertility transition, they document a causal positive effect of improving life-expectancy on economic growth. With contrast to the present paper they infer causality from IV estimates and not from Grangercausality and do not investigate the long-run determinants of fertility behavior.

More closely related to our approach is the work of Wang et al. (1994); Eckstein et al. (1999); Angeles (2010), and Murtin (2012). Wang et al. use a structural VAR model and US data from the second half of the twentieth century and document the endogeneity of fertility in a cointegrated system together with output and employment. The impact of mortality is not investigated. Eckstein et al. use long-run Swedish data from 1751 to 1990 to fit a five-period overlapping generation model, which takes child mortality and income as (exogenous) determinants of fertility. They identify a negative impact of income on fertility and child mortality as the most important factor explaining the fertility decline. Interestingly, they also find that child mortality is not sufficient to explain the secular fall of net fertility. For that rising income is essential.

Like us, Angeles (2010) and Murtin (2012) use panel data. Angeles employs the Arellano and Bond (1991) difference-GMM estimator to account for the potential endogeneity of fertility and finds that a fall in mortality induces a significant reduction in fertility while the

Footnote 2 continued

Hazan and Berdugo 2002; Doepke 2004; Strulik 2004). Moav (2005) generates a negative impact of income on fertility by assuming a preference for child quality and that bearing children involves time costs whereas educating children involves monetary costs (Moav 2005).

3 There exists a relatively large literature on fertility in pre-modern times, i.e. times for which Malthusian theory predicts a positive association between fertility and income and a negative association between population density and income. See, among others, Eckstein et al. (1984); Galloway (1988); Lee and Anderson (2002); Nicolini (2007), and Ashraf and Galor (2011). Microeconometric evidence is compiled in Schultz (1997). 
impact of GDP per capita on fertility is statistically insignificant. Murtin, using the Blundell and Bond (1998) system-GMM estimator, reports that neither per capita income nor mortality has a robust significant effect on fertility. His results suggest that years of primary schooling are the only robust determinant of fertility.

However, dynamic panel GMM techniques are not without problems. The concern that weak instruments typically bias coefficient estimates towards their unadjusted counterparts (OLS or fixed-effects estimates) applies as much to panel GMM as to cross-section estimators. Bun and Windmeijer (2010), for example, show that the weak instrument problem - previously attributed to the Arellano-Bond difference GMM estimator-is equally problematic for the Blundell-Bond system approach. Roodman (2009) warns that the BlundellBond estimator may give a false sense of certainty as a large number of internal instruments can overfit the endogenous variables and may weaken the power of the Sargan test. Moreover, it is well-known (and in detail documented by Reher 2004) that the lag structure between mortality decline and fertility decline differs widely across countries. For a sample of more than one hundred countries we thus expect problems arising from the assumption of a common lag structure. We are therefore confident that our cointegration approach advances the state-of-the art empirical research on the long-run determinants of fertility.

\section{Empirical model and data}

Since it may take a long time before changes in mortality and the standard of living are reflected in changes in fertility, we adopt an empirical specification that captures the long-run relationship between these variables. In this section, we present the empirical specification, discuss some econometric issues, and describe the data.

\subsection{Empirical specification and econometric issues}

Our basic empirical model is given by

$$
\text { fert }_{i t}=a_{i}+\beta_{1} \cdot \text { mort }_{i t}+\beta_{2} \cdot \log \left(g d p_{i t}\right)+e_{i t}
$$

where $i=1,2, \ldots, N$ and $t=1,2, \ldots, T$ are country and time indices, fer $_{i t}$ is fertility, measured by the crude birth rate (births per thousand population), and mort $t_{i t}$ stands for mortality, measured by the crude death rate (deaths per thousand population). We use the crude death rate and not infant or child mortality because the crude death rate captures more effectively the full effect of mortality on fertility including effects from adult longevity (later on we check robustness of our results by substituting infant mortality into the regression). In general, the total fertility rate would have been a better measure of current fertility than the crude birth rate because it is not affected by the age distribution of the population. Total fertility rates, however, are not available for a sufficiently large number of countries over the last century. Using crude birth and death rates, however, provides also an advantage in that we can readily infer from our estimates the impact of mortality decline on population growth.

The level of economic development is represented by GDP per capita, $g d p_{i t}$, measured in $\operatorname{logs}$, as is common practice in the related empirical literature. Moreover, the measurement in logs has important implications with respect to the underlying test of demo-economic theory. To see this, differentiate (1) and obtain the change of fertility $\mathrm{d} f$ ert $t_{i t}$ as a function of the change of mortality dmort $t_{i t}$ and of the growth rate of GDP per capita, $\mathrm{d} g d p_{i t} / g d p_{i t}$. With respect to the demographic transition Eq. (1) thus stipulates that fertility change is associated with income growth as suggested by unified growth theory. 
The $\beta$ coefficients in (1) capture the long-run effects of mortality and income on fertility. Because our principal interest is on long-run effects, it is not essential to be concerned about the variable lags through which mortality and per capita income affect fertility. Finally, we include country-specific fixed effects, $a_{i}$, to control for country-specific factors that are relatively stable over time, such as geography and culture.

Equation (1) assumes a long-run trivariate relationship between permanent movements in the crude birth rate, the crude death rate, and the log level of GDP per capita. Necessary conditions for this assumption to hold are that the individual time series for fertility, mortality, and per capita income are nonstationary or, more specifically, integrated of the same order and that fert $_{i t}$, mort $_{i t}$, and $\log \left(g d p_{i t}\right)$ form a cointegrated system. ${ }^{4}$

A specific advantage of the cointegration framework is that a regression consisting of cointegrated variables has a stationary error term, implying that no relevant integrated variables are omitted. Any omitted non-stationary variable that is part of the cointegrating relationship would enter the error term $e_{i t}$, thereby producing non-stationary residuals and failure to detect cointegration. If, on the other hand, there is cointegration between a set of variables, then the same stationary relationship exists also in an extended variable space (see, e.g., Johansen 2000); if the variables are nonstationary and not cointegrated, the error term is nonstationary as well, and Eq. (1) would in this case represent a spurious regression in the sense of Granger and Newbold (1974).

These features are particularly important with respect to education as an omitted variable. Theory, in particular unified growth theory, as well as other other empirical studies (e.g. the work of Schultz 1997; Angeles 2010; Murtin 2012) suggest that education is an important explanatory variable for fertility besides mortality and income. Here we have not considered education in the first steps of our analysis because the purpose of the paper is to scrutinize the effects of income growth and mortality change on fertility change over the last century and education data is not available as a long enough time series for sufficiently many countries for the whole last century. It is thus important to emphasize that the cointegration tests described below imply that omitted education does not bias our results on the long-run relationship between mortality, fertility, and income. In order to demonstrate this feature, we use in Sect. 4.2. A smaller sample of countries with less time series data (due to the limited availability of education data) and include in our robustness checks several measures of education. ${ }^{5}$

The existence of a long-run relationship between fertility, income and mortality does not exclude the possibility of long-run Granger-causality running from fertility to GDP per capita and mortality. According to neoclassical growth theory, for example, high population growth due to increased fertility lowers income per capita because capital is spread more thinly over the population. On the other hand, population growth plays quite a different role in many R\&D-based models of endogenous growth (Romer 1990; Jones 1995). Strictly interpreted, i.e. in the sense that "more people means more Isaac Newtons and therefore more ideas" (Jones 2003), these theories predict that higher population growth leads to higher economic growth and thus to higher income per capita. Finally, an increase in fertility may also lead

\footnotetext{
4 Since our system has three variables, the existence of one cointegrating relationship would imply that there are two permanent shocks, or common trends, and one transitory shock (Stock and Watson 1988). There are, of course, a number of factors and mechanisms that could be the driving forces behind permanent and temporary shocks. Potential candidates for the two common trends are productivity and health trends, while, for example, changes in the age structure or deaths due to war could be viewed as temporary shocks.

5 There are, of course, potentially several others factors conceivable that influence fertility (such as government policy and health status). Adding further variables may result in further cointegrating relationships. Since the cointegration property is invariant to extensions of the information set, the inclusion of additional variables would, however, not destroy the original cointegrating relationship (Lütkepohl 2007). This justifies to consider small "subsystems", such as Eq. (1), if the variables are cointegrated.
} 
to an increase in mortality because a larger number of children per household could entail fewer resources available to invest in health of each child (Strulik 2008).

The overall empirical implication is that it is not only crucial to examine the timeseries properties of the variables and to test whether the variables are cointegrated, but it is also important to deal with these endogeneity problems and to investigate the direction of causality.

\subsection{Data and descriptive statistics}

The analysis of the long-run relationship between fertility, mortality, and income requires the use of data over a long time window. Therefore, we select a sample of countries for which continuous data are available over a 100 year period from 1900 to 1999. Data on birth and death rates are from the database compiled by David Reher (2004) and data on (real) per capita GDP are from Maddison (2003), available at http://dx.doi.org/10.1787/456125276116. Since Reher's data are averaged over five years, we use 5 year averages of all variables. (20 time series observations per country). An estimator of cointegrating vectors constructed with temporally aggregated data is consistent (see, e.g., Granger 1990) and asymptotically as efficient as the estimator based on disaggregated time series, when, as in our case, all the variables in the cointegrating vector are flows (see, e.g., Chambers 2003). Chambers (2001), for example, demonstrates that estimates from cointegrating regressions are remarkable stable across frequencies, which is consistent with the well-known finding that the power of unit root and cointegration tests depends far more on the time span than on the number of observations (see, e.g, Shiller and Perron 1985; Hakkio and Rush 1991; Lahiri and Mamingi 1995).

We include all countries with complete time series, resulting in a balanced panel with 400 observations and 20 countries. As illustrated in Fig. A.1 in the Appendix, these countries are geographically dispersed around the world, located in North America (Canada), Central America (Mexico), South America (Argentina, Chile, Colombia, Uruguay, and Venezuela), Europe (Belgium, Denmark, Finland, France, Italy, Netherlands, Norway, Portugal, Spain, Sweden, and Switzerland), South Asia (Sri Lanka), and East Asia (Japan).

In the figures in Appendix A1 we show the data for each country separately over the period 1900-1999. As can be seen, fertility and mortality exhibit a decreasing trend in all cases except for Denmark where mortality declined from 1900 to 1954 and then rose between 1955 and 1999 (see Fig. A.2, row 2, column 2). Real GDP per capita, in contrast, exhibits a strong upward trend in all countries. Overall, the time-series evolution is consistent with the possibility that $f e r t_{i t}$, mort $_{i t}$, and $\log \left(g d p_{i t}\right)$ are nonstationary and cointegrated, an observation which we confirm by several panel unit root test and panel cointegration tests (Appendix A1 and A2).

Table 1 lists the countries along with the average values of the crude birth and death rates and average GDP per capita over the period of observation. As expected, there are large cross-country differences in the values of these parameters. Mexico is the country with the highest fertility rate, followed by Venezuela, Colombia, and Chile, while Belgium ranks at the bottom of the fertility scale. Mexico is also the country with the highest mortality rate, followed by Chile, Sri Lanka, and Colombia. Average income is highest in Switzerland, and lowest in Sri Lanka, Colombia, and Mexico. Altogether, it appears that countries with higher mortality rates and lower per capita income tend to have higher fertility rates, suggesting a positive relationship between fertility and mortality and a negative relationship between fertility and income.

The last column in Table 1 reports the year of the onset of the fertility transition as identified by Reher (2004). In all but two countries (Sweden and Uruguay) the fertility 
Table 1 Countries and country summary statistics

Numbers for birth rates and death rates (in per thousand) and for GDP are country averages 1900-1999. Onset of the transition is the year of onset of the fertility transition as identified by Reher (2004)

\begin{tabular}{llrrl}
\hline & $\begin{array}{l}\text { Crude birth } \\
\text { rate }\end{array}$ & \multicolumn{1}{l}{$\begin{array}{l}\text { Crude death } \\
\text { rate }\end{array}$} & $\begin{array}{l}\text { GDP per } \\
\text { capita }\end{array}$ & $\begin{array}{l}\text { Onset of } \\
\text { transition }\end{array}$ \\
\hline Argentina & 27.12 & 11.67 & 5356.13 & 1910 \\
Belgium & 16.61 & 12.94 & 8189.49 & 1905 \\
Canada & 22.64 & 9.50 & 9224.20 & 1915 \\
Chile & 34.02 & 17.70 & 4186.88 & 1960 \\
Colombia & 38.57 & 16.14 & 2532.02 & 1965 \\
Denmark & 18.89 & 11.02 & 9159.57 & 1910 \\
Finland & 20.57 & 12.85 & 6694.22 & 1915 \\
France & 16.70 & 13.93 & 8014.96 & 1900 \\
Italy & 20.46 & 13.66 & 6813.96 & 1925 \\
Japan & 24.14 & 13.19 & 6425.85 & 1950 \\
Mexico & 40.88 & 19.92 & 3280.14 & 1970 \\
Netherlands & 20.89 & 9.96 & 8586.86 & 1910 \\
Norway & 18.55 & 10.92 & 8043.81 & 1905 \\
Portugal & 24.11 & 14.78 & 4107.80 & 1925 \\
Spain & 22.32 & 14.28 & 4901.11 & 1910 \\
Sri Lanka & 33.33 & 16.64 & 1516.44 & 1960 \\
Sweden & 16.64 & 11.62 & 8553.14 & 1865 \\
Switzerland & 17.47 & 11.40 & 10971.08 & 1910 \\
Uruguay & 22.89 & 10.44 & 4516.13 & 1890 \\
Venezuela & 39.01 & 15.54 & 5937.70 & 1965 \\
\hline
\end{tabular}

transition began in 20th century, indicating that we focus indeed on the most interesting century of demographic change. Twelve countries experienced the onset in the first half of the last century while 6 countries experienced it in the second half. The large variation of the onset of the transition across countries could be one explanation for the problem of earlier studies (by focussing on individual countries or across countries on a single year or on a shorter time period) in identifying a general pattern for the long-run determinants of fertility.

\section{Empirical analysis}

The pre-tests for unit-roots and cointegration, which are reported in the Appendix, suggest that the variables are nonstationary and cointegrated, as assumed in Eq. (1). ${ }^{6}$ In this section, we provide estimates of the cointegrating relationship between fertility, mortality, and income, test the robustness of the estimates, and investigate the direction of causality between the three variables.

\footnotetext{
6 Two or more non-stationary variables are cointegrated if there exists a linear combination of these variables that is stationary. Cointegration, in the traditional, linear sense, therefore implies that the long-run relationship between the variables is linear.
} 


\subsection{Long-run relationship}

In order to estimate the long-run elasticities of fertility with respect to mortality and per capita income, we use the dynamic ordinary least squares (DOLS) estimator. This estimator is asymptotically equivalent to Johansen's (1988) system estimator. It generates unbiased and asymptotically efficient estimates of the long run relationship, even with endogenous regressors (see, for example, Stock and Watson 1993), thus allowing us to control for the potential endogeneity of mortality and per capita income. In addition, it is well-known that in small $T$ samples (like ours) the DOLS estimator performs better than other available estimators, like, for example, the FIML estimator of Johansen's (1988) or the fully modified ordinary least squares (FMOLS) estimator of Phillips and Hansen (1990). This is true for time series models as well as for panel data models (see, e.g., Stock and Watson 1993; Kao and Chiang 2000; Wagner and Hlouskova 2010). Following Kao and Chiang (2000), the within-dimension-based DOLS model for our research question is given by (2).

$$
\begin{aligned}
\text { fert }_{i t}= & a_{i}+\beta_{1} \cdot \text { mort }_{i t}+\beta_{2} \cdot \log \left(g d p_{i t}\right)+\sum_{j=-k}^{k} \Phi_{1 i j} \Delta \text { mort }_{i t-j} \\
& +\sum_{j=-k}^{k} \Phi_{2 i j} \Delta \log \left(g d p_{i t-j}\right)+\epsilon_{i t}
\end{aligned}
$$

where $\Phi_{1 i j}$ and $\Phi_{2 i j}$ are coefficients of lead and lag differences which account for possible serial correlation and endogeneity of the regressors, thus yielding unbiased estimates of $\beta_{1}$ and $\beta_{2}$. The results of this estimation procedure are presented in the first row of Table 2 where, for brevity, we report only the estimated $\beta$ coefficients. The coefficient on mort $_{i t}$ is highly significant and positive, while the GDP per capita variable has a highly significant negative coefficient.

Our estimates imply that a reduction of the mortality rate is associated with an increase of the population growth rate holding GDP constant. ${ }^{7}$ From that we conclude that declining mortality is insufficient to explain the declining population growth observed along the path of demographic transition. Although mortality is identified as an important driver of decreasing fertility, GDP growth is essential in order to explain the secular decline of population growth.

Finally, in the bottom part of Table 2, we present the results of some diagnostic tests. JB is a Jarque-Bera test for normality, RESET is a Ramsey RESET test for general nonlinearity and functional form misspecification, HET stands for a Breusch-Pagan-Godfrey test for heteroscedasticity, $\operatorname{LM}(k), k=1,3$, are Lagrange Multiplier tests for autocorrelation based on one and three lags, and STABILITY is an $L c$ type panel test for parameter instability in the style of Hansen (1992). ${ }^{8}$ All statistics presented in the diagnostics are Fisher (1932) statistics, defined as $\lambda=-2 \sum_{i} \log \left(p_{i}\right)$, where $p_{i}$ is the $p$ value of the country-specific

\footnotetext{
7 This can be readily observed from the coefficient of mortality being smaller than one. Fertility and mortality are both measured as crude births and deaths, respectively, per 1,000 population, thus the difference between the two is net-fertility/population growth.

8 The Lc test statistic is a Lagrange multiplier test of the null hypothesis of constant parameters against the alternative that the parameters follow a martingale process. It has the advantage that the timing of the structural break is treated as unknown. Because our panel test statistic for parameter stability is a Fisher (1932) statistic which in turn is based on computing the Lc statistics for each country separately, the timing of the possible structural shift is allowed to vary across countries.
} 
Table 2 Long-run relationship of fertility with mortality and GDP

\begin{tabular}{lll}
\hline & mort $t_{i t}$ & $\log \left(g d p_{i t}\right)$ \\
\hline Within-dimension DOLS estimator & $0.378^{* *}(7.40)$ & $-5.246^{* *}(-10.18)$ \\
$\quad$ Kao and Chiang (2000) & & \\
DOLS mean group estimator & $0.747^{* *}(9.04)$ & $-5.489^{* *}(-12.83)$ \\
$\quad$ Pedroni (2001) & $0.880^{* *}(10.45)$ & \\
CCE mean group estimator & & \\
$\quad$ Pesaran (2006) & $0.855^{* *}(11.33)$ & \\
2-step estimator & & $-4.456^{* *}(-11.23)$ \\
$\quad$ Breitung (2005) & & \\
Diagnostic tests & & \\
JB & & $18.73[0.998]$ \\
RESET & & $45.07[0.268]$ \\
HET & & $36.60[0.624]$ \\
LM(1) & $39.09[0.511]$ \\
LM(3) & $46.42[0.225]$ \\
STABILITY & $42.69[0.356]$ \\
\hline The & & \\
\hline
\end{tabular}

The dependent variable is fert $_{i t}$

$t$ Statistics in parentheses

The DOLS regression was estimated with one lead and one lag (as suggested by the Schwarz criterion)

All statistics presented in the diagnostics are Fisher (1932) statistics, which are based on the country-specific diagnostic tests of the respective DOLS model

The Fisher statistic is distributed as $\chi^{2}$ with $2 \times N$ degrees of freedom

The numbers in brackets are the corresponding $p$ values

** Indicate significance at the $1 \%$ level

diagnostic test of the respective DOLS model; the Fisher statistic is distributed as $\chi^{2}$ with $2 \times N$ degrees of freedom. ${ }^{9}$

As can be seen, all test statistics reject the respective null hypothesis, suggesting that neither obvious nonlinearity nor misspecification is present, that the residuals show no signs of non-normality, autocorrelation or autoregressive heteroscedasticity, and that the estimated parameters are stable. Since parameter constancy may imply a cointegrating relationship, whereas parameter instability and structural change can lead to the finding of no cointegration,

\footnotetext{
9 The purpose for using diagnostic tests is to verify the overall adequacy of a model. Tests for normality, autocorrelation, heteroskedasticity, misspecification, and instability are tests that are routinely applied in time series studies to assess whether a model can be described as well-specified. Unfortunately, there is a lack of diagnostic testing procedures in panel econometrics. In the words of Banerjee et al. (2010), p. 2: "By and large, panel estimation is a misspecification-test-free zone." Assuming that diagnostic testing is equally important in a panel as in the time-series context, it is necessary to find a way to modify the time-series diagnostics in a panel context. For this purpose, we pool the diagnostic test statistics of the individual countries by calculating Fisher (1932) statistics. This approach has also been used by Banerjee et al. (2010), who investigate the performance of several modified time-series diagnostic tests in panel data. Banerjee et al. $(2010,34)$ conclude, based on Monte Carlo studies of several panel estimators, that "estimators, properly defined and constructed, do have sound residual properties and diagnostic tests based on these estimators do have power in detecting misspecification, which if unaccounted for can lead to serious deficiencies in the interpretation of empirical results."
} 
the finding of stability is consistent with the finding that $f e r t_{i t}, \operatorname{mort}_{i t}$, and $\log \left(g d p_{i t}\right)$ are cointegrated without a structural break in the cointegrating vector. ${ }^{10}$

\subsection{Robustness checks}

To assess the robustness of our conclusions, we perform several sensitivity checks. First, we investigate whether the estimates are robust to alternative estimation methods. Specifically, a potential problem with the above estimation procedure could be that it assumes homogeneous $\beta$ coefficients, which may be empirically incorrect. Countries differ widely in terms of economic structure, institutions, government policy, and other characteristics, implying that the effects of mortality and income on fertility could also differ across countries. To allow the slope coefficients to vary across countries, we use the between-dimension, group-mean panel DOLS estimator suggested by Pedroni (2001). This estimator involves estimating separate DOLS regressions for each country and averaging the long-run coefficients, $\hat{\beta}=N^{-1} \sum_{i=1}^{N} \hat{\beta}_{i}$. The $t$ statistic for the average coefficient is calculated as the sum of the individual $t$ statistics divided by the root of the number of cross-sectional units, $t_{\hat{\beta}}=\sum_{i=1}^{N} t_{\hat{\beta}_{i}} / \sqrt{N}$. We present the DOLS group-mean point estimates of the effects of mortality and income on fertility in the second row of Table 2.

Because the DOLS estimates could be biased in the presence of cross-sectional dependence, we also report (in the third row) the result of the common correlated effects (CCE) mean group estimator suggested by Pesaran (2006). ${ }^{11}$ Compared to the use of common time dummies (to control for cross-sectional dependence through common time effects), as is common practice in panel studies, the CCE mean group estimator has the advantage that it allows for cross-sectional dependencies arising from multiple unobserved common factors, and that it permits the individual responses to the common factors to differ across countries. It augments the cointegrating regression with the cross-sectional averages of the dependent variable and the observed regressors as proxies for the unobserved factors (see Eq. (A.8) in the Appendix). Kapetanios et al. (2011) have recently shown that the CCE estimator is consistent regardless of whether the common factors are stationary or nonstationary.

The idea behind the inclusion of common time dummies is to extract common time effects from the data in order to account for cross-sectional dependence through common time effects. However, for this approach to be effective in eliminating or reducing the cross-sectional dependence, the cross-sectional dependence must be driven by a single common source, and the response to the common factor must be the same for all countries (Pedroni 2007). We estimated the DOLS model also with time dummies. The results, which are qualitatively similar to those in Table 2, are reported and discussed in the Appendix.

\footnotetext{
10 Of course, we cannot exclude the possibility that in some individual countries some individual time series have a unit root with a structural break. Identifying structural breaks in time series data is subtle and tricky, especially when the number of time series observations is small, and is beyond the scope of this paper. The crucial point for our analysis is that, even if some of the individual time series had a structural break, it would not imply a structural break in the cointegrating relationship between the series; it may well be that the cointegrating relationship is stable, and this is exactly what we find.

11 Cross sectional dependence can arise due to several factors, such as omitted observed common factors, unobserved common factors, or spatial spillover effects. For example, the data may be in part driven by common global business cycles or health shocks. Shocks affecting fertility and mortality (and income) in several countries at the same time include major influenza epidemics, the spread of HIV/AIDS, the introduction of new vaccines, and the diffusion of antibiotics and contraceptives.
} 
For completeness, we also present estimates obtained using the two-step estimator suggested by Breitung (2005). While the estimators discussed above are single equation techniques, the vector error-correction model (VECM) estimator of Breitung is a system approach. It involves estimating the Johansen's (1988) VECM (given by Eq. A.9 in the Appendix) separately for each country to obtain the country-specific error-correction coefficients $a_{i}$. In the second step, the estimated $a_{i}$ s are used to estimate the cointegration matrix $\beta$ by running a pooled regression of $\hat{z}_{i t}$ on $y_{t-1}^{(2)}$, where $\hat{z}_{i t}=\left(\hat{\alpha}_{i}^{\prime} \widehat{\sum}_{i}^{-1} \hat{\alpha}_{i}\right)^{-1} \hat{\alpha}_{i}^{\prime} \widehat{\sum}_{i}^{-1} \Delta y_{i t}$ $-y_{t-1}^{(1)}$ and $y_{i t}=\left[y_{t-1}^{(1)}, y_{t-1}^{(2)}\right] \cdot y_{t-1}^{(1)}$ and $y_{t-1}^{(2)}$ are $r \times 1$ and $(p-r) \times 1$ sub-vectors of $y_{i t}$.

As can be seen from Table 2, all four estimators provide qualitatively similar results, suggesting that both the positive association of mortality with fertility and the negative association of GDP per capita with fertility are neither due to potentially restrictive homogeneity assumptions, nor due to possible cross-sectional dependence, nor due to the single-equation specification. As expected, the between-dimension DOLS estimator produces larger estimates (in absolute value) than its within-dimension counterpart, a result that is in line with the findings of Pedroni (2001). More specifically, the magnitude of the mortality coefficient is about half as large for the within-dimension DOLS estimator compared to the other three estimators. For GDP per capita, the coefficients are fairly similar across the two DOLS and the CEE models, while the GDP per capita coefficient obtained by the two-step system estimator is substantially larger in magnitude. Thus, our main conclusions still hold, albeit less strongly for the inferred association with population growth.

Given the limited number of time-series observations in our sample, the mean group results (which are based on individual time-series regressions) should be interpreted with caution. In addition, the CCE mean group estimator is intended for the case in which the regressors are exogenous, so that we lose the ability to account for the likely endogeneity of mortality and per capita GDP. Also, it is worth mentioning that there is evidence to suggest that the efficiency gains from pooling are likely to offset the potential biases due to individual heterogeneity (see, e.g., Baltagi and Griffin 1997). In addition, Wagner and Hlouskova (2010) found that the pooled DOLS estimator outperforms all other estimators-both single equation and system estimators. We are thus convinced that the pooled within-dimension panel DOLS estimator is the most appropriate one and continue our robustness analysis for this estimator.

In order to verify that the positive and negative coefficients of $m o r t_{i t}$ and $\log \left(g d p_{i t}\right)$ are not due to potential outliers we re-estimate the DOLS regression excluding one country at a time from the sample. The sequentially estimated coefficients and their $t$ statistics are presented in Fig. 1. They indicate that the coefficients of mort $_{i t}$ are always significantly positive (and relatively stable between 0.344 and 0.392$)$ and that the coefficients of $\log \left(g d p_{i t}\right)$ are always significantly negative (and relatively stable between -5.581 and -4.882 ). We conclude that our results are robust to potential outliers.

Next, we examine whether the positive relationship between fertility and mortality, as well as the negative relationship between fertility and income are due to sample-selection bias. Sample-selection bias occurs when the selected sample is not random and thus not representative. Admittedly, a potential problem with our sample could be that it includes only 20 countries. We therefore re-estimate the DOLS regression for a second sample with 1,190 observations for 119 countries over the period from 1950 to 1999 (again using 5 year averages). The sample of countries (listed in Appendix A4) is now much more heterogenous and includes also the latecomers of the demographic transition from Asia and Africa. 

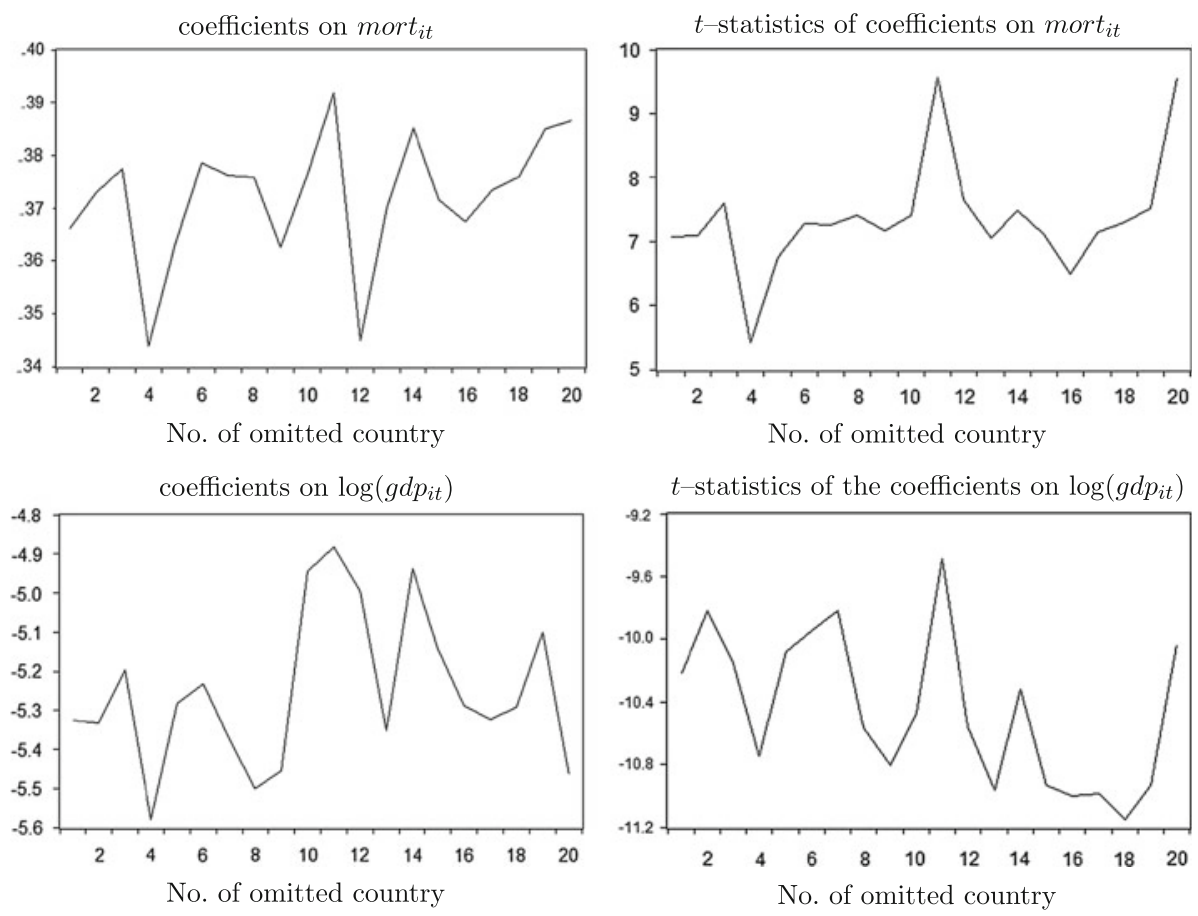

Fig. 1 DOLS estimation with single country excluded from the sample

Table 3 DOLS estimates: 119 countries 1950-1999

\begin{tabular}{llc}
\hline infantmort $_{i t}$ & mort $_{i t}$ & $\log \left(g d p_{i t}\right)$ \\
\hline $0.141^{* *}(21.20)$ & $0.420^{* *}(13.74)$ & $-5.829^{* *}(-11.46)$ \\
& & $-3.029^{* *}(-9.06)$ \\
\hline
\end{tabular}

The dependent variable is fert $_{i t}$

$t$ Statistics in parentheses

The DOLS regression was estimated with one lead and one lag (as suggested by the Schwarz criterion)

** Indicate significance at the $1 \%$ level

The results based on this sample are reported in Table 3. The second row shows the estimated coefficients on the crude death rate and log GDP per capita (the original variables), while the third row presents DOLS estimates using the infant mortality rate, labeled inf antmort ${ }_{i t}$, in place of the crude death rate to examine also the robustness of the results to alternative measures of mortality. The data sources are the same as described above. As can be seen from the table, the long-run associations of mortality and GDP per capita with fertility are still positive and negative, respectively, regardless of which sample and mortality measure is used, indicating that the results are robust to different samples and measures of mortality.

Another way to examine whether a stable cointegrating relation is a reasonable approximation of the data is to estimate the cointegrating vector over different time periods (Lettau and Ludvigson 2004). The fact that the estimated coefficients for the period 1950-1999 are strikingly similar to those for the period 1900-1999 (0.42 and -5.8 in Table 3 compared to 
Table 4 DOLS estimates for subsamples

\begin{tabular}{llll}
\hline & mort & $\log \left(g d p_{i t}\right)$ & $\begin{array}{l}\text { No. of countries in } \\
\text { subsample }\end{array}$ \\
\hline $\begin{array}{l}\text { 20-country sample } \\
\text { Developed countries }\end{array}$ & $0.623^{* *}(6.25)$ & $-4.757^{* *}(-8.22)$ & 12 \\
Developing countries & $0.470^{* *}(5.45)$ & $-4.021^{* *}(-3.50)$ & 8 \\
$\begin{array}{l}\text { 119-country sample } \\
\text { Developed countries }\end{array}$ & $0.502^{* *}(5.96)$ & $-5.567^{* *}(-4.03)$ & 16 \\
Developing countries & $0.487^{* *}(10.45)$ & $-4.987^{* *}(-9.83)$ & 103 \\
\hline
\end{tabular}

The dependent variable is fert $_{i t}$

$t$ Statistics in parentheses

The DOLS regression was estimated with one lead and one lag (as suggested by the Schwarz criterion). A country is classified as a developing (non-OECD) country if it was between 1961 (when the OECD was founded) and 1999 less than $75 \%$ of the time a member of the OECD

** Indicate significance at the $1 \%$ level

0.38 and -5.2 in Table 2) suggests that our results are not sensitive to the sample period. This finding is consistent with the stability test result presented in Table 2. Given, however, that the time period of the estimation in Table 3 is half of that for the estimation in Table 2, we prefer the results in Table 2 .

We next investigate whether our results are driven by developed or relatively rich countries. To this end, we split both the 20-country and 119-country samples into two sub-samples: developed (OECD) and developing (non-OECD) countries. The resulting coefficients are listed in Table 4. Regardless of which sub-sample is chosen, the coefficient on mort $_{i t}$ is significantly positive, while the coefficient on $\log \left(g d p_{i t}\right)$ is significantly negative. Remarkably, there appear to be no significant differences in the associations of mortality and economic development with fertility between rich and poor countries.

Finally, we examine the sensitivity of our results to the inclusion of education. Following Murtin (2012), we use three measures of education: average years of schooling (schooling st $_{\text {), }}$ average years of primary schooling (schooling $P_{i t}$ ), and average years of secondary and tertiary schooling (schooling $S T_{i t}$ ) in the total population over 15 . The data are from Morrisson and Murtin (2009) and are only available every ten years beginning in 1870 (see http://www. pse.ens.fr/data/), forcing us to use decade averages of $f e r t_{i t}$, mort $_{i t}$, and $\log \left(g d p_{i t}\right)$ (since Reher (2004) reports birth and death rates as 5 year averages). All countries with complete data for the period from 1900 to 1999 are included, resulting in a balanced panel with 18 countries $^{12}$ and 10 time-series observations per country (180 observations).

As Table 5 shows, the estimated coefficients on $\operatorname{mort}_{i t}$, and $\log \left(g d p_{i t}\right)$ do not change qualitatively if education is added as an explanatory variable. Interestingly, primary schooling is the only significant education variable (with the expected negative sign), which is consistent with the results of Murtin (2012). On the other hand, our results differ from Murtin's in that we find that both mortality and income are also significantly associated with fertility. Of course, given the small cross-section and time-series dimensions of the panel, caution is needed when

12 Argentina, Belgium, Canada, Chile, Denmark, Finland, France, Italy, Japan, Mexico, Netherlands, Norway, Portugal, Spain, Sweden, Switzerland, Uruguay, and Venezuela 
Table 5 DOLS estimates with education

\begin{tabular}{lllll}
\hline mort $_{i t}$ & $\log \left(g d p_{i t}\right)$ & schooling $_{i t}$ & schooling $P_{i t}$ & schooling $S T_{i t}$ \\
\hline $0.452^{* *}(5.72)$ & $-8.771^{* *}(-11.68)$ & $-0.053(-0.35)$ & & \\
$0.342^{* *}(5.33)$ & $-5.225^{* *}(-5.94)$ & & $-0.703^{* *}(-2.65)$ & \\
$0.396^{* *}(6.12)$ & $-7.163^{* *}(-8.09)$ & & & $0.323(1.32)$ \\
\hline
\end{tabular}

The dependent variable is ert $_{i t}$

schooling $_{i t}$ is average years of schooling in the total population over 15 , schooling $P_{i t}$ is average years of primary schooling in the total population over 15 , schooling $S T_{i t}$ is average years of secondary and tertiary schooling in the total population over 15

$t$ Statistics in parentheses

The DOLS regression was estimated with one lead and one lag (as suggested by the Schwarz criterion)

** Indicate significance at the $1 \%$ level

interpreting these results. Nevertheless, although the education-fertility relationship is not our subject here, our estimates suggest that education is an important explanatory variable. ${ }^{13}$

\subsection{Causality}

Standard growth models predict that higher fertility lowers per capita GDP because physical capital is spread more thinly over the population. An increase in fertility may also lead to an increase in mortality because a larger number of children entails less resources available per child for nutrition and health. Consequently, causality may run from $\operatorname{mort}_{i t}$ and $\log \left(g d p_{i t}\right)$ to ert $_{i t}$, from $f e r t_{i t}$ to $\log \left(g d p_{i t}\right)$ and from $f e r t_{i t}$ to mort $_{i t}$.

To test the direction of causality, we use a two-step procedure. In the first step, we employ the (within) DOLS estimate of the long-run relationship to construct the disequilibrium term

$$
e c_{i t}=\text { fert }_{i t}-\left[\hat{a}_{i}+0.378 \cdot \text { mort }_{i t}-5.246 \log \left(g d p_{i t}\right)\right] .
$$

In the second step, we estimate the vector error correction model (VECM)

$$
\left(\begin{array}{l}
\Delta \text { fert }_{i t} \\
\Delta \text { mort }_{i t} \\
\Delta \log \left(g d p_{i t}\right)
\end{array}\right)=\left(\begin{array}{l}
c_{1 i} \\
c_{2 i} \\
c_{3 i}
\end{array}\right)+\sum_{j=1}^{k} \Gamma_{j}\left(\begin{array}{l}
\Delta \text { fert }_{i t-j} \\
\Delta \text { mort }_{i t-j} \\
\Delta \log \left(g d p_{i t-j}\right)
\end{array}\right)+\left(\begin{array}{l}
a_{1} \\
a_{2} \\
a_{3}
\end{array}\right) e c_{i t-1}+\left(\begin{array}{l}
\epsilon_{1 i t} \\
\epsilon_{2 i t} \\
\epsilon_{3 i t}
\end{array}\right)
$$

where the error-correction term $e c_{i t-1}$ represents the deviation from the equilibrium and the adjustment coefficients $a_{1}, a_{2}$, and $a_{3}$ capture how $f e r t_{i t}$, mort $_{i t}$, and $\log \left(g d p_{i t}\right)$ respond to deviations from the equilibrium relationship.

From the Granger representation theorem we know that at least one of the adjustment coefficients must be nonzero if a long-run relationship between the variables exists. A significant error-correction term also suggests long-run Granger causality, and thus long-run endogeneity (see, e.g., Hall and Milne 1994), whereas a non-significant adjustment coefficient implies weak exogeneity and no long-run Granger causality running from the independent to the dependent variable(s). ${ }^{14}$

\footnotetext{
13 We also checked the robustness of our results using the (balanced panel) data from Murtin (2012). These results, which are reported in the Appendix, are very similar to those in Table 2.

14 In cointegrated systems we have to distinguish between short-run Granger noncausality (through the lagged differenced explanatory variables) and long-run Granger noncausality (through the error-correction term). Testing the null hypothesis of no long-run Granger causality is equivalent to testing the null hypothesis of weak exogeneity. Weak exogeneity is a necessary (but not sufficient condition) for Granger noncausality in cointegrated systems.
} 
Table 6 Weak exogeneity tests/long-run causality tests

\begin{tabular}{llll}
\hline & $\begin{array}{l}\text { Weak exogeneity of... } \\
\text { fert } \\
\left(\text { significance of } a_{1}\right)\end{array}$ & $\begin{array}{l}\operatorname{mort}_{\text {it }} \\
\left(\text { significance of } a_{2}\right)\end{array}$ & $\begin{array}{l}\log \left(g d p_{i t}\right) \\
\left(\text { significance of } a_{3}\right)\end{array}$ \\
\hline$\chi^{2}(1)$ & 56.88 & 6.23 & 8.35 \\
$p$ values & $(0.000)$ & $(0.013)$ & $(0.004)$ \\
\hline
\end{tabular}

The number of degrees of freedom $v$ in the standard $\chi^{2}(v)$ tests correspond to the number of zero restrictions The number of lags was determined by the general-to-specific procedure with a maximum of three lags

In the following, we test for weak exogeneity of fertility, mortality, and the level of economic development-and thus for long-run Granger noncausality between ert $_{i t}$, mort $_{i t}$, and $\log \left(g d p_{i t}\right)$. We begin with eliminating the insignificant short-run dynamics in the model successively according to the lowest $t$ values (until the remaining variables are significant at the five-percent level). Then we test the significance of the adjustment coefficients. This approach has been used by Hendry (1995, Chap. 16), Urbain (1995); Juselius (2001); Lütkepohl and Wolters $(1998,2003)$, and Herzer (2008), among others, to reduce the number of estimated parameters (according to Hendry's general-to-specific methodology) and to increase the precision of the weak exogeneity tests on the $a$ coefficients. ${ }^{15}$ Since all variables in the model, including $e c_{i t-1}$, are stationary (because the level variables are integrated of order 1 and cointegrated), a conventional likelihood ratio test can be used to test the null hypothesis of weak exogeneity, $H_{0}: a_{1,2,3}=0$.

Table 6 presents the results. The error correction terms are significantly different from zero in each equation, implying that the null hypothesis of weak exogeneity can be rejected for $f_{e r t} t_{i}$, mort $_{i t}$, and $\log \left(g d p_{i t}\right)$ at least at the $5 \%$ level. Thus, the weak exogeneity tests suggest that all variables are endogenous in the long run, from which it can be concluded that the statistical long-run causality indeed runs from $m o r t_{i t}$ and $\log \left(g d p_{i t}\right)$ to $f e r t_{i t}$, from fert $t_{i t}$ to $\log \left(g d p_{i t}\right)$, and from fert $_{i t}$ to mort $_{i t}$.

To test the robustness of this conclusion, we calculate generalized impulse responses from the full VAR-VECM system (with two lags). ${ }^{16}$ Unlike traditional impulse response analysis (see, e.g. Lütkepohl and Reimers 1992), which considers orthogonalized shocks based on the Cholesky decomposition, the generalized impulse response approach of Pesaran and Shin (1998) desirably yields unique impulse response functions that are invariant to the ordering of variables. It accounts for contemporaneous correlation of the residuals by examining the shock in one of the variables, and then integrating out the effects of the other shocks according to the observed distribution of errors.

Figure 2 shows the responses of fertility to a one-standard-deviation innovation in mortality, the responses of mortality to one-standard-deviation impulse in fertility, the responses of fertility to a one-standard-deviation innovation in log GDP per capita, and the responses of $\log$ GDP per capita to one-standard-deviation impulse in fertility over a 50 year horizon; the dashed lines mark plus and minus two standard errors obtained through Monte Carlo simulations using 1,000 replications.

The upper panels focus on the interaction between fertility and mortality. As the left panel shows, mortality has a gradual and permanent effect on fertility that reaches its full impact

\footnotetext{
15 The results (available on request) do not change substantially when alternative lag selection methods are used.

16 We also experimented with VEC specifications of different lag orders, $k=1,3$, and found qualitatively similar results.
} 

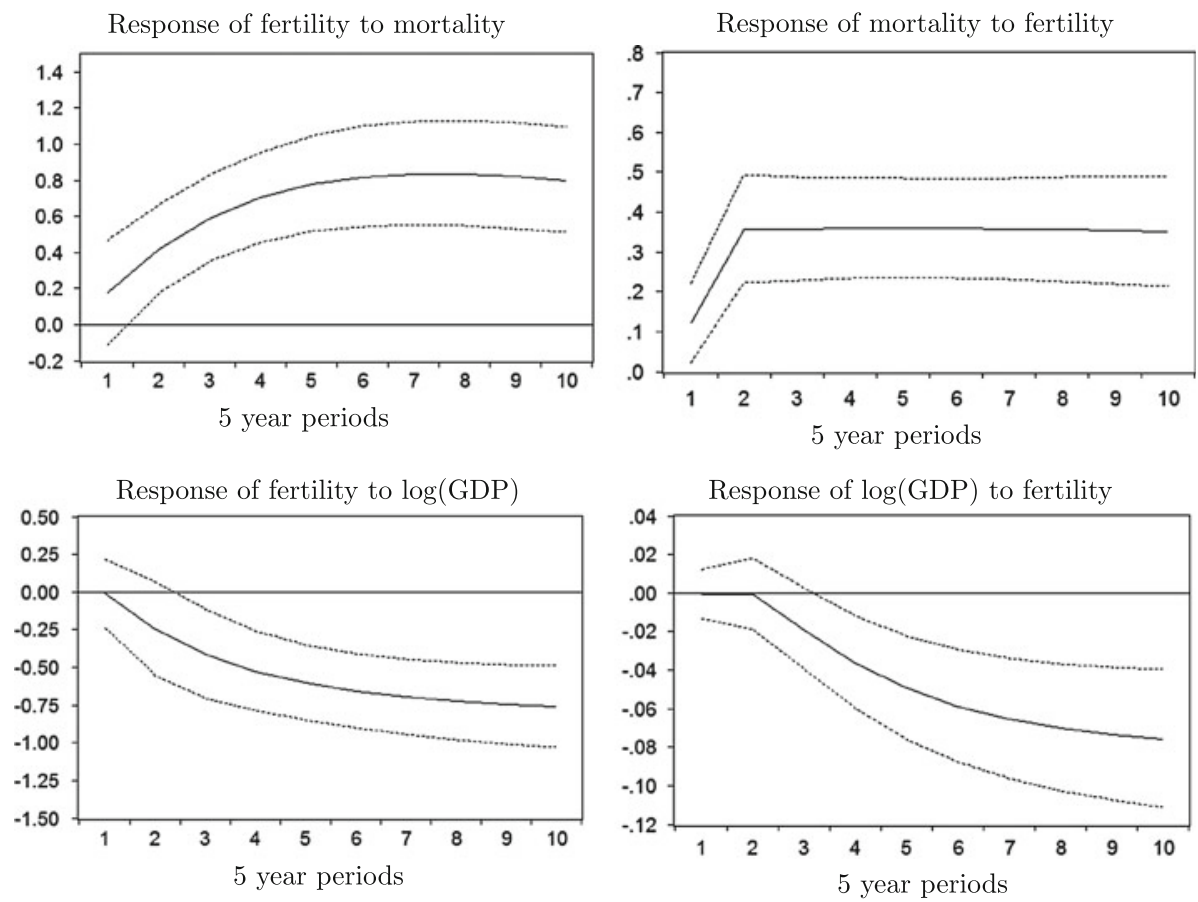

Fig. 2 Impulse-responses

not before 6 periods (30years) after the shock (i.e. after about one generation) and that is not statistically significant in the first period. This is consistent with the widespread belief in demography that fertility behavior reacts only gradually on declining mortality. The upper right panel confirms that there is also a significant positive feedback effect of fertility on mortality; it reaches its maximum in the second period.

The bottom panels in Fig. 2 show the GDP-fertility interaction. The left panel indicates that fertility gradually and permanently decreases in response to a one-standard-deviation innovation in log GDP per capita and that the response becomes statistically different from zero after the second period. The lower right panel documents that there is also a (delayed) negative effect of fertility on GDP. It becomes statistically significant after about 15 years, i.e. at about the time when the individuals born 15 years ago begin to enter the workforce. This pattern of response of GDP per capita suggests that the dependency effect, which occurs immediately at birth when GDP is subdivided among more people, becomes only significant when it is amplified by the capital dilution effect, which occurs when the extra population enters the workforce. The observed response of GDP is inconsistent with the mechanism proposed by R\&D-based growth theory (strictly interpreted). Our results do not support the view that more people cause income per capita to grow.

Taken together and keeping in mind that GDP is measured in logs, the impulse-response pattern and the Granger-causality tests confirm empirically - and to our best knowledge for the first time - that the virtuous cycle, which has been stressed so much in development economics and in unified growth theory, does indeed exist: Growth of income per capita leads to reduced fertility, which in turn causes income growth to rise further, which leads to a further decline of fertility etc. Low fertility is both a cause and consequence of successful economic development. 


\section{Concluding remarks}

Given the available data from the last century our analysis has shown that (1) declining mortality leads to declining fertility, that (2) growth of income per capita leads to declining fertility, that (3) declining mortality per se is insufficient to explain the secular decline of population growth over the last century, and that (4) fertility changes are both cause and consequence of economic development such that the income-fertility interaction provides a virtuous cycle of demo-economic development. We have furthermore shown that these conclusions are robust to alternative estimation methods, potential outliers, sample selection, different measures of mortality, the sample period, and the inclusion of education.

Under the prospect of perpetual income growth the result that there exists a linear negative relationship between income and fertility (and thus between fertility change and income growth) may appear to be puzzling. After all, fertility and mortality are bounded to be nonnegative and cannot continue to fall infinitely with forever rising income. The evidence derived from historical data, however, does not mean that the empirical model predicts a persistence of this association for the (infinite) future.

With income growing further, the association between income growth and fertility change has to become non-linear sooner or later and eventually it must disappear. The correct assessment of our results is that so far (i.e. over the last century) a linear model describes the data adequately, a fact that we have proven with extensive tests. The implied conclusion is thus that the leveling-off of fertility's reaction on income growth is not yet visible in the data by the end of the 20th century.

Acknowledgments The authors' would like to thank David Reher for sharing the data. The authors' thank David Canning, Jesus Crespo Cuaresma, Carl-Johan Dalgaard, Michael Funke, six anonymous referees, and the editor, Oded Galor, for useful comments and suggestions.

Open Access This article is distributed under the terms of the Creative Commons Attribution License which permits any use, distribution, and reproduction in any medium, provided the original author(s) and the source are credited.

\section{Appendix A1: Key variables by country over the sample period}

See Figs. A.1, A.2, A.3 and A.4.

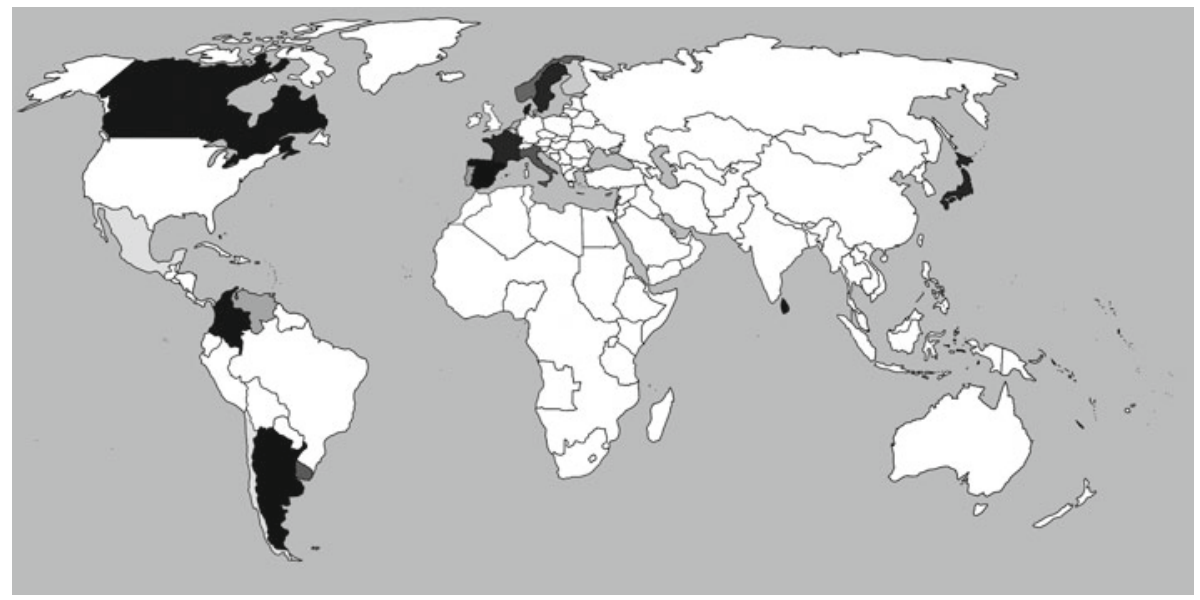

Fig. A.1 The 20 countries of our main sample on a map 

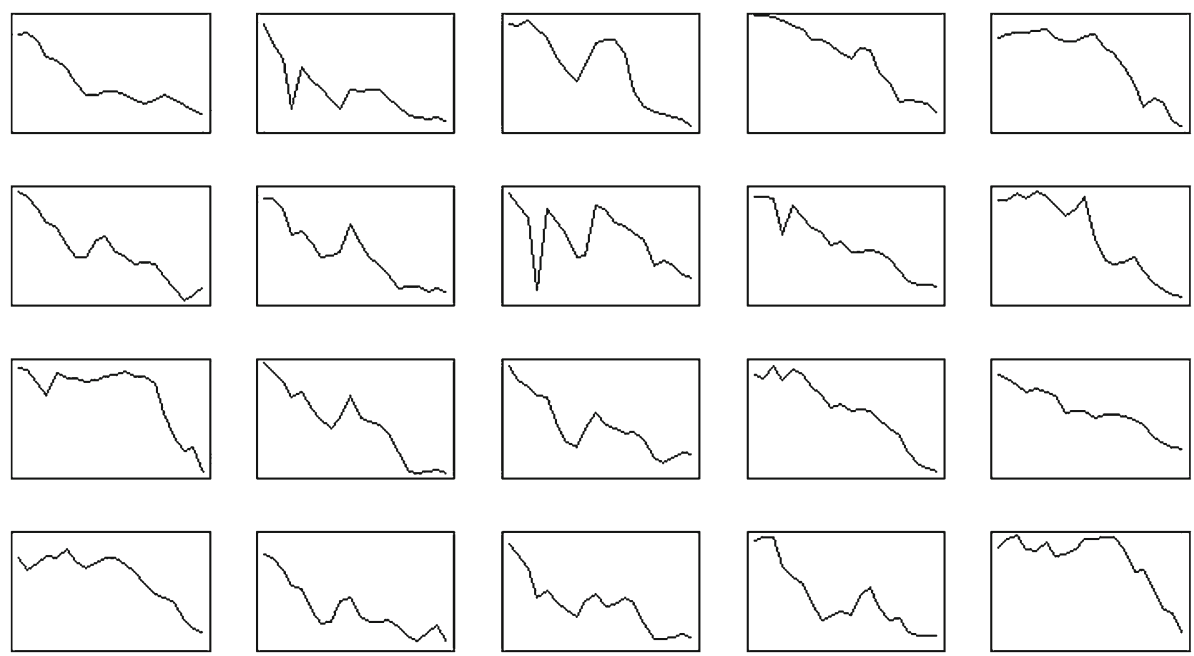

Fig. A.2 Fertility by country over the period 1900-1999. The countries from the left to the right are: Argentina, Belgium, Canada, Chile, Colombia, Denmark, Finland, France, Italy, Japan, Mexico, Netherlands, Norway, Portugal, Spain, Sri Lanka, Sweden, Switzerland, Uruguay, and Venezuela
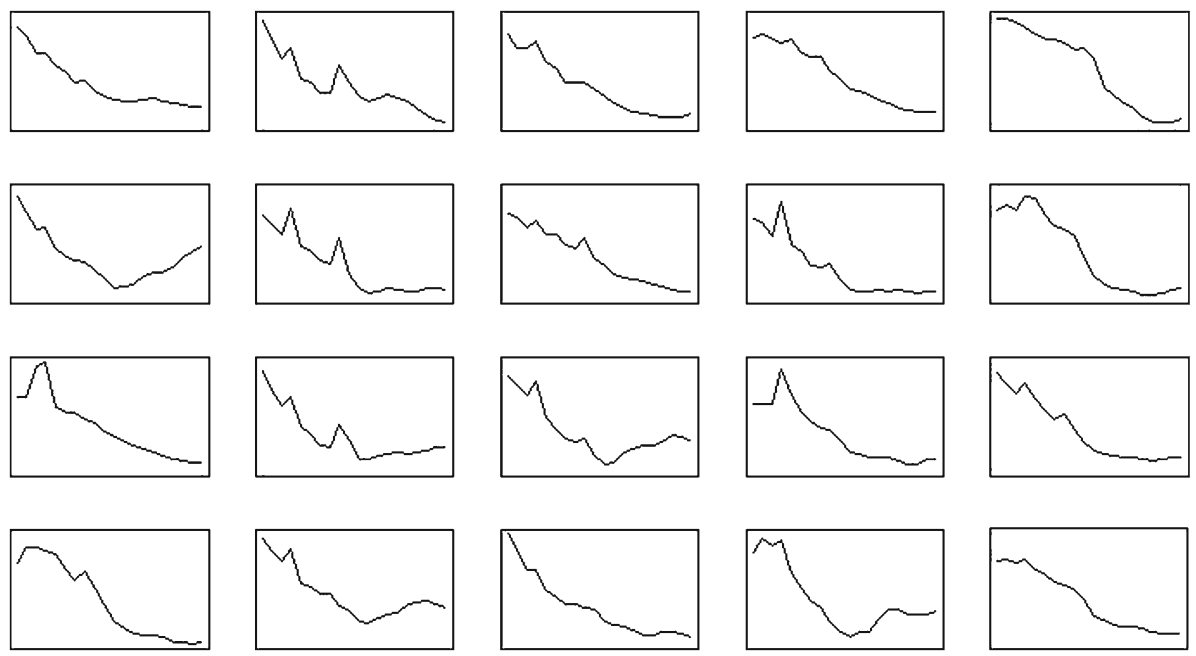

Fig. A.3 Mortality by country over the period 1900-1999. The countries from the left to the right are: Argentina, Belgium, Canada, Chile, Colombia, Denmark, Finland, France, Italy, Japan, Mexico, Netherlands, Norway, Portugal, Spain, Sri Lanka, Sweden, Switzerland, Uruguay, and Venezuela 

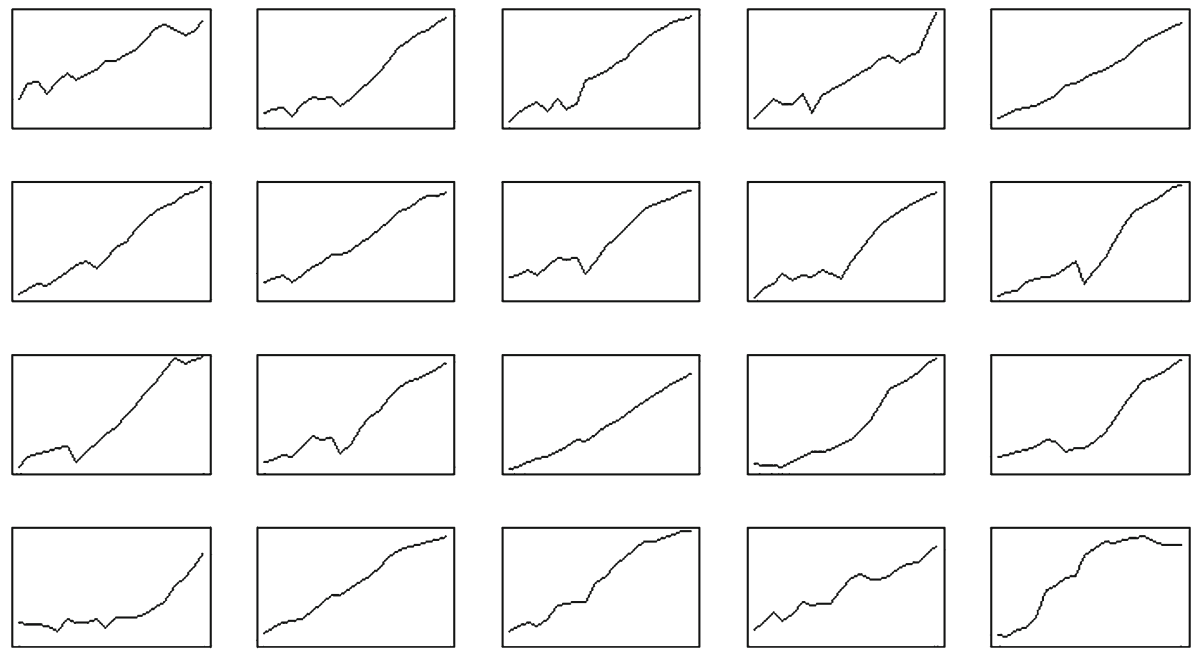

Fig. A.4 Log GDP per capita by country over the period 1900-1999. The countries from the left to the right are: Argentina, Belgium, Canada, Chile, Colombia, Denmark, Finland, France, Italy, Japan, Mexico, Netherlands, Norway, Portugal, Spain, Sri Lanka, Sweden, Switzerland, Uruguay, and Venezuela

\section{Appendix A2: Panel unit-root tests}

In order to investigate the time-series properties of the data, we use the Levin, Lin, and Chu (2002)(LLC), the Im, Pesaran, and Shin (2003) (IPS), and the cross-sectionally augmented IPS test of Pesaran (2007). All these tests are based on an augmented Dickey-Fuller (ADF) regression where the variable of interest is observed for $N(=20)$ cross-sectional units and $T(=20)$ time periods:

$$
\Delta x_{i t}=z_{i t} \gamma_{i}+z_{i t} \rho_{i} x_{i t-1}+\sum_{j=1}^{k_{i}} \varphi_{i j} \Delta x_{i t-1}+\epsilon_{i t}, \quad i=1,2, \ldots, N, \quad t=1,2, \ldots, T
$$

where $k_{i}$ is the lag length, $z_{i t}$ is a vector of deterministic terms, such as fixed effects or fixed effects plus individual trends, and $\gamma_{i}$ is the corresponding vector of coefficients.

The within-dimension-based LLC panel unit-root test pools the autoregressive coefficient across the countries during the unit-root test and thus restrict the first-order autoregressive parameter to be the same for all countries, $\rho_{i}=\rho$. Thus, the null hypothesis is that all series contain a unit root, $H_{0}: \rho=0$, while the alternative hypothesis is that no series contains a unit root, $H_{1}: \rho=\rho_{i}<0$, that is, all are (trend) stationary.

To conduct the LLC-test statistic, the following steps are performed. The first step is to obtain the residuals, $\hat{e}_{i t}$, from individual regressions of $\Delta x_{i t}$ on its lagged values (and on $\left.z_{i t}\right), \Delta x_{i t}=\sum_{j=1}^{k_{i}} \theta_{1 i j} \Delta x_{i t-j}+z_{i j} \gamma_{i}+e_{i t}$. Second, $x_{i t-1}$ is regressed on the lagged values of $\Delta x_{i t}$ (and on $z_{i t}$ ) to obtain $\hat{v}_{i t-1}$, that is, the (lagged) residuals of this regression, $x_{i t}=$ $\sum_{j=1}^{k_{i}} \theta_{2 i j} \Delta x_{i t-j}+z_{i j} \gamma_{i}+v_{i t}$. In the third step, $\hat{e}_{i t}$ is regressed on $\hat{v}_{i t-1}, \hat{e}_{i t}=\delta \hat{v}_{i t-1}+\xi_{i t}$. The standard error, $\hat{\sigma}_{e i}^{2}$, of this regression is then used to normalize the residuals $\hat{e}_{i t}$ and $\hat{v}_{i t-1}$ (to control for heterogeneity in the variances of the series), $\tilde{e}_{i t}=\hat{e}_{i t} / \hat{\sigma}_{e i}^{2}, \tilde{v}_{i t-1}=\hat{v}_{i t-1} / \hat{\sigma}_{e i}^{2}$. Finally, $\rho$ is estimated from a regression of $\tilde{e}_{i t}$ on $\tilde{v}_{i t-1}, \tilde{e}_{i t}=\rho \tilde{v}_{i t-1}+\xi_{i t}$. The conventional 
$t$ statistic for the autoregressive coefficient $\rho$ has a standard normal limiting distribution if the underlying model does not include fixed effects and individual time trends $\left(z_{i t}\right)$. Otherwise, this statistic has to be corrected using the first and second moments tabulated by Levin et al. (2002) and the ratio of the long-run variance to the short-run variance, which accounts for the nuisance parameters present in the specification. The limiting distribution of this corrected statistic is normal as $N \rightarrow \infty$ and $T \rightarrow \infty$.

In contrast to the LLC test, the between-dimension-based IPS panel unit-root test allows the first-order autoregressive parameter to vary across countries by estimating the ADF equation separately for each country. Thus, the null hypothesis is that each series contains a unit-root, $H_{0}: \rho_{i}=0$ for all $i$, while the alternative hypothesis is that at least one of the individual series in the panel is (trend) stationary, $H_{1}: \rho_{i}<0$ for at least one $i . H_{0}$ is tested against $H_{1}$ using the standardized $t$ bar test statistic

$$
\Gamma_{i}=\frac{\sqrt{N}\left[\bar{t}_{N T}-\mu\right]}{\sqrt{v}}
$$

where $\bar{t}_{N T}$ is the average of the $N$ cross-section ADF $t$ statistics, and $\mu$ and $v$ are, respectively, the mean and variance of the average of the individual $t$ statistics, tabulated by Im et al. (2003). The standardized $t$ bar statistic converges to a standard normal distribution as $N$ and $T \rightarrow \infty$.

However, both the LLC and the IPS test procedures assume cross-sectional independence and thus may lead to spurious inference if the errors, $\epsilon_{i t}$, are not independent across $i$. Therefore, we also use the cross-sectionally augmented IPS test, which allows for cross-sectional dependence by augmenting the ADF regression with the cross-section averages of lagged levels and first-differences of the individual series. An attractive feature of this test is that it permits the individual countries to respond differently to the common time effects as reflected by the country-specific coefficients on the cross-section averages of the variables. The crosssection augmented ADF (CADF) regression, carried out separately for each country, is given by

$$
\Delta x_{i t}=z_{i t} \gamma_{i}+\rho x_{i t-1}+\sum_{j=1}^{k_{i}} \varphi_{i j} \Delta x_{i t-j}+\alpha_{i} \bar{x}_{t-1}+\sum_{j=0}^{k_{i}} \eta_{i j} \Delta \bar{x}_{t-j}+v_{i t}
$$

where $\bar{x}_{t}$ is the cross-section mean of $x_{i t}, \bar{x}_{t}=N^{-1} \sum_{i=1}^{N} x_{i t}$. The cross-section augmented IPS statistic is a simple average of $t_{i}$ defined by

$$
C I P S=N^{-1} \sum_{i=1}^{N} t_{i}
$$

where $t_{i}$ is the OLS $t$ ratio of $\rho_{i}$ in the above CADF regression. Critical values are tabulated by Pesaran (2007).

Table A.1 reports the results of these tests for the variables in levels and in first differences. As can be seen, all three test statistics are unable to reject the null hypothesis that fert $_{i t}$, mort $_{i t}$, and $\log \left(g d p_{i t}\right)$ have a unit-root in levels. Since the unit-root hypothesis can be rejected for the first differences, it can be concluded that all series are integrated of order one, $I(1)$. 
Table A.1 Panel unit root tests

\begin{tabular}{lllll}
\hline Variables & Deterministic terms & LLC statistics & IPS statistics & CIPS statistics \\
\hline Levels & & & & \\
$\quad$ ert $_{i t}$ & $c, t$ & 0.46 & -0.72 & -2.08 \\
mort $_{i t}$ & $c, t$ & 2.1 & 4.06 & -2.3 \\
$\log \left(g d p_{i t}\right)$ & $c, t$ & -0.46 & 0.4 & -2.32 \\
First differences & & & & \\
$\quad \Delta f$ ert $_{i t}$ & $c$ & $-6.38^{* *}$ & $-6.17^{* *}$ & $-2.55^{* *}$ \\
$\Delta$ mort $_{i t}$ & $c$ & $-1.75^{*}$ & $-3.49^{* *}$ & $-2.41^{* *}$ \\
$\Delta \log \left(g d p_{i t)}\right.$ & $c$ & $-2.71^{* *}$ & $-3.31^{* *}$ & $-2.44^{* *}$ \\
\hline
\end{tabular}

$c(t)$ indicates that we allow for different intercepts (and time trends) for each country

Two lags were selected to adjust for autocorrelation

The relevant $1 \%(5 \%)$ critical value for the CIPS statistics is $-2.92(-2.73)$ with an intercept and a linear trend, and $-2.40(-2.21)$ with an intercept

** (*) Denote significance at the $1 \%(5 \%)$ level

\section{Appendix A3: Panel cointegration tests}

We use several panel cointegration test procedures to determine whether there is a long-run relationship between fertility, mortality, and economic development. The first is the twostep residual-based procedure suggested by Pedroni (1999, 2004), which can be intuitively described as follows. In the first step, the hypothesized cointegrating regression

$$
\text { fert }_{i t}=a_{i}+\beta_{1 i} \text { mort }_{i t}+\beta_{2 i} \log \left(g d p_{i t}\right)+\epsilon_{i t}
$$

is estimated separately for each country, thus allowing for heterogeneous cointegrating vectors. In the second step, the residuals, $\hat{\epsilon}_{i t}$, from these regressions are tested for stationarity. To test the null hypothesis of non-stationarity (or no cointegration) Pedroni proposes seven statistics. Here, we employ the two statistics with the highest power for small $T$-panels like ours: the panel ADF and group ADF statistics (see, e.g., Pedroni 2004; Wagner and Hlouskova 2010. The former is analogous to the LLC (2002) panel unit root test, while the latter is analogous to the IPS (2003) panel unit root test (both discussed above). The standardized distributions for the test statistics are given by

$$
\kappa=\frac{\varphi-\mu \sqrt{N}}{\sqrt{v}} \Rightarrow N(0,1) .
$$

where $\varphi$ is the respective ADF panel or group ADF statistic, and $\mu$ and $v$ are the expected mean and variance of the corresponding statistic, tabulated by Pedroni (1999).

In addition, we use the panel cointegration tests developed by Kao (1999). Kao follows basically the same approach as Pedroni (1999, 2004), but constrains the cointegrating coefficients to be homogeneous across countries by employing a within regression of the form

$$
\text { fert }_{i t}=a_{i}+\beta_{1} \text { mort }_{i t}+\beta_{2} \log \left(g d p_{i t}\right)+e_{i t} .
$$

To test the stationarity of the residuals, $\hat{e}_{i t}$, from this regression Kao presents four withindimension-based DF test statistics and one within-dimension-based ADF statistic: The first two DF statistics, $D F_{\rho}$ and $D F_{t}$, as well as the ADF statistic, assume strict exogeneity of the regressors, while the other two DF-type tests, $D F_{\rho}^{*}$ and $D F_{t}^{*}$, do not require this assumption. 
$D F_{\rho}$ and $D F_{\rho}^{*}$ are calculated based on the estimated first-order autoregressive coefficient in the panel DF regression; the associated $t$ statistic is used in calculating $D F_{t}$ and $D F_{t}^{*}$.

The problem with these two approaches is that they do not take into account potential error cross-sectional dependence, which could bias the results. To test for cointegration in the presence of possible cross-sectional dependence we use the two-step residual-based procedure suggested by Holly et al. (2010), who apply the CCE estimator of Pesaran (2006) in the first-step regression. Like the cross-sectionally augmented IPS test, the CCE estimator allows for cross-sectional dependencies that potentially arise from multiple unobserved common factors and permits the individual responses to these factors to differ across countries. In our case, the cross-section augmented cointegrating regression (for the $i$ th cross-section) is given by

$$
\text { fert }_{i t}=a_{i}+\beta_{1 i} \text { mort }_{i t}+\beta_{2 i} \log \left(g d p_{i t}\right)+g_{1 i} \overline{\text { fert }_{t}}+g_{2 i} \overline{\text { mort }_{t}}+g_{3 i} \overline{\log \left(g d p_{t}\right)}+\xi_{i t}
$$

where the cross-section averages $\overline{\text { fert }_{t}}=N^{-1} \sum_{i=1}^{N}$ fert $_{i t}, \overline{\text { mort }_{t}}=N^{-1} \sum_{i=1}^{N}$ mort $_{i t}$ and $\overline{\log \left(g d p_{t}\right)}=N^{-1} \sum_{i=1}^{N} \log \left(g d p_{i t}\right)$ serve as proxies for the unobserved factors. In the second step, we compute the cross-section augmented IPS statistic for the residuals from the individual CCE long-run relations $\hat{\mu}=\operatorname{fert}_{i t}-\hat{\beta}_{1 i}$ mort $_{i t}-\hat{\beta}_{2 i} \log \left(g d p_{i t}\right)$, including an intercept. In doing so, we account for unobserved common factors that could be correlated with the observed regressors in both steps.

However, residual-based (panel) cointegration tests restrict the long-run elasticities to be equal to the short-run elasticites. If this restriction is invalid, residual-based (panel) cointegration tests may suffer from low power (see, e.g., Westerlund 2007). Another drawback of single-equation, residual-based (panel) cointegration tests is that they are generally not invariant to the normalization of the cointegrating regression, and, moreover, such tests are unable to identify more than one cointegrating relationship in systems with more than two variables. Therefore, we also use the Larsson et al. (2001) procedure, which is based on Johansen's (1988) system approach. Like the Johansen time-series cointegration test, the Larsson et al. panel test treats all variables as potentially endogenous, thus avoiding normalization problems inherent in residual-based cointegration tests. In addition, the Larsson et al. procedure allows the long-run elasticities to differ from the short-run elasticities and hence does not impose a possibly invalid common factor restriction. Finally, an important feature of the Larsson et al. approach is that it allows the determination of the number of cointegrating vectors.

The Larsson et al. approach involves estimating the Johansen vector VECM for each country separately:

$$
\Delta y_{i t}=\Pi_{i} y_{i t-1}+\sum_{i=1}^{k_{i}} \Gamma_{i k} \Delta y_{i t-k}+z_{i t} \gamma_{i}+\epsilon_{i t}
$$

where $y_{i t}$ is a $p \times 1$ vector of endogenous variables $\left(y_{i t}=\left[\right.\right.$ fert $\left._{i t}, \operatorname{mort}_{i t}, \log \left(g d p_{i t}\right]^{\prime}\right) ; p$ is the number of variables) and $\Pi_{t}$ is the long-run matrix of order $p \times p$. If $\Pi_{i}$ is of reduced rank, $r_{i}<p$, it is possible to let $\Pi_{i}=\alpha_{i} \beta_{i}$, where $\beta_{i}$ is a $p \times r_{i}$ matrix, the $r_{i}$ columns of which represent the cointegrating vectors, and $\alpha_{i}$ is a $p \times r_{i}$ matrix whose $p$ rows represent the error correction coefficients. The null hypothesis is that all of the $N$ countries in the panel have a common cointegrating rank, i.e. at most $r$ (possibly heterogeneous) cointegrating relationships among the $p$ variables: $H_{0}: \operatorname{rank}\left(\Pi_{i}\right)=r_{i} \leq r$ for all $i=1, \ldots, N$, whereas the alternative hypothesis is that all the cross-sections have a higher rank: $H_{1}: \operatorname{rank}\left(\Pi_{i}\right)=p$ 
for all $i=1, \ldots, N$. To test $H_{0}$ against $H_{1}$, a panel cointegration rank trace-test statistic is computed by calculating the average of the individual trace statistics, $L R_{i T}\{H(r) \mid H(p)\}$.

$$
\overline{L R}_{N T}\{H(r) \mid H(p)\}=\frac{1}{N} \sum_{i=1}^{N} L R_{i T}\{H(r) \mid H(p)\}
$$

and then standardizing it as follows:

$$
\Psi_{\overline{L R}}\{H(r) \mid H(p)\}=\frac{\sqrt{N}\left[\overline{L R}_{N T}\{H(r) \mid H(p)\}-E\left(Z_{k}\right)\right]}{\sqrt{\operatorname{Var}\left(Z_{k}\right)}} \Rightarrow N(0,1) .
$$

The mean $E\left(Z_{k}\right)$ and variance $\operatorname{Var}\left(Z_{k}\right)$ of the asymptotic trace statistic are tabulated by Breitung (2005) for the model we use (the model with a constant in the cointegrating vector and a linear trend in the data). However, a well-known problem is that the Johansen trace statistics tend to over-reject the null in small samples. To avoid the Larsson et al. test also overestimating the cointegrating rank, we compute the standardized panel trace statistics based on small-sample corrected country-specific trace statistics. More specifically, to adjust the individual trace statistics we use the small-sample correction factor suggested by Reinsel and Ahn (1992):

$$
L_{i T}\{H(r) \mid H(p)\} \times\left[\frac{T-k_{i} \times p}{T}\right] .
$$

The results of these tests are presented in Table A.2. As can be seen, all tests strongly suggest that $f$ ert $_{i t}$, mort $_{i t}$, and $\log \left(g d p_{i t}\right)$ are cointegrated. The standardized trace statistics clearly supports the presence of one cointegrating vector. Also, the CIPS, the Kao, and

\begin{tabular}{|c|c|c|c|}
\hline \multicolumn{4}{|l|}{ Pedroni $(1999,2004)$} \\
\hline \multicolumn{2}{|l|}{ Panel ADF t-statistic } & \multicolumn{2}{|l|}{$-3.82^{* *}$} \\
\hline \multicolumn{2}{|l|}{ Group ADF t-statistic } & \multicolumn{2}{|l|}{$-3.24^{* *}$} \\
\hline \multicolumn{4}{|l|}{ Као (1999) } \\
\hline$D F_{\rho}$ statistic & \multicolumn{3}{|c|}{$-3.38^{* *}$} \\
\hline$D F_{t}$ statistic & \multicolumn{3}{|c|}{$-2.45^{* *}$} \\
\hline$A D F_{t}$ statistic & \multicolumn{3}{|c|}{$-3.38^{* *}$} \\
\hline$D F_{\rho}^{*}$ statistic & \multicolumn{3}{|c|}{$-3.69^{* *}$} \\
\hline$D F_{t}^{*}$ statistic & \multicolumn{3}{|c|}{$-2.67^{* *}$} \\
\hline \multicolumn{4}{|l|}{ Holly et al. (2010) } \\
\hline CIPS statistic & \multicolumn{3}{|c|}{$-2.47^{* *}$} \\
\hline \multirow[t]{2}{*}{ Larsson et al. (2001) } & \multicolumn{3}{|c|}{ Cointegration rank } \\
\hline & $\mathrm{r}=0$ & $r=1$ & $r=2$ \\
\hline Standardized panel trace statistics & $4.70 * *$ & 0.01 & 1.51 \\
\hline
\end{tabular}
the Pedroni statistics reject the null hypothesis of no cointegration at the 1 level, implying

Table A.2 Cointegration tests 
that there exists a single long-run relationship between fertility, mortality, and economic development.

\section{Appendix A4: Countries in the sample for Table 3}

Algeria, Angola, Argentina, Austria, Bahrain, Bangladesh, Belgium, Benin, Bolivia, Botswana, Brazil, Bulgaria, Burkina Faso, Burundi, Cambodia, Cameroon, Canada, Central African Republic, Chad, Chile, China, Colombia, Comoros, Congo (Dem. Rep.), Congo (Rep.), Costa Rica, Cote d'Ivoire, Cuba, Denmark, Djibouti, Dominican Republic, Ecuador, Egypt, El Salvador, Finland, France, Gabon, Gambia, Germany, Ghana, Guatemala, Guinea, Guinea Bissau, Haiti, Honduras, Hungary, India, Indonesia, Iran, Iraq, Israel, Italy, Jamaica, Japan, Jordan, Kenya, Korea (Republic), Kuwait, Laos, Lebanon, Lesotho, Liberia, Libya, Madagascar, Malawi, Malaysia, Mali, Mauritania, Mauritius, Mexico, Mongolia, Morocco, Mozambique, Myanmar, Namibia, Nepal, Netherlands, Nicaragua, Niger, Nigeria, North Korea , Norway, Oman, Panama, Paraguay, Peru, Philippines, Portugal, Puerto Rico, Qatar, Romania, Rwanda, Saudi Arabia, Senegal, Seychelles, Sierra Leone, Singapore, Somalia, South Africa, Spain, Sri Lanka, Sudan, Swaziland, Sweden, Switzerland, Syria, Tanzania, Thailand, Togo, Trinidad and Tobago, Tunisia, Uganda, United States, Uruguay, Venezuela, Vietnam, Yemen, Zambia, and Zimbabwe.

\section{Appendix A5: Further robustness tests}

As a further robustness check, we first re-estimate the DOLS regression with time dummies. The first row of Table A.3 presents the results. They qualitatively confirm the results in Table 2 , although the coefficient on the income variable (-2.149) is much lower (in absolute value) than its counterpart in Table $2(-5.246)$. This could be due to two reasons:

First, as discussed in Sect. 4.2, the implicit assumption behind the use of common time dummies is that the cross-sectional dependence induced by common time effects is driven by a single common source and that all countries respond in the same way to the common factors. This assumption is not very realistic. Second, since the coefficients on the time dummies follow a negative trend, the common time effects and the $(\log )$ incomes of the countries in our sample are highly correlated. The correlation coefficients range from -0.91 (Spain) to -0.69 (Uruguay), suggesting that multicollinearity between log GDP per capita and the trending time effects is a problem.

It is well known that there is always a certain degree of collinearity between stochastic and deterministic trends in small samples, and that, therefore, depending on the degree of collinearity, the inclusion of a time trend can lead to seriously biased estimates. To further assess whether this collinearity affects our main results, we re-estimate the DOLS regression both with a common deterministic trend and country-specific time trends. The estimation results are presented in the second and third rows of Table A.3. The coefficients on $\log \left(g d p_{i t}\right)$ are again lower than the corresponding coefficients in Table 2, but still negative and significant.

Finally, the DOLS regression is also re-estimated with data from Murtin (2012). Since (panel) cointegration techniques require the use of continues time series data, we use his balanced panel data set, which contains 10 year data for 16 countries over the period 1870-2000 (14 time series observations per country). The results are reported in Table A.4. Again, the 
Table A.3 DOLS estimates with time dummies, common deterministic trend, and country-specific linear trends

\begin{tabular}{lll}
\hline & mort $_{i t}$ & $\log \left(g d p_{i t}\right)$ \\
\hline With time dummies & $0.222^{* *}(3.60)$ & $-2.149^{* *}(-2.15)$ \\
With a common deterministic trend & $0.330^{*}(2.15)$ & $-1.832^{*}(-2.09)$ \\
With country-specific time trends & $0.260^{*}(2.13)$ & $-3.036^{*}(-2.44)$ \\
\hline
\end{tabular}

The dependent variable is fert $_{i t}$

$t$ Statistics in parentheses

The number of leads and lags was determined by the Schwarz criterion with a maximum number of three lags

** (*) Indicate significance at the $1 \%(5 \%)$ level

Table A.4 Estimates with data from Murtin (2012)

\begin{tabular}{lll}
\hline & mort $_{i t}$ & $\log \left(g d p_{i t}\right)$ \\
\hline Without time dummies & $0.782^{* *}(9.69)$ & $-4.163^{* *}(-5.56)$ \\
With time dummies & $0.506^{* *}(5.72)$ & $-3.399^{*}(-2.59)$ \\
\hline
\end{tabular}

The dependent variable is fert $_{\text {it }}$

$t$ Statistics in parentheses

The DOLS regression was estimated with one lead and one lag (as suggested by the Schwarz criterion)

$* *(*)$ Indicate significance at the $1 \%(5 \%)$ level

coefficient on mort $_{i t}$ is positive, while the coefficient on $\log \left(g d p_{i t}\right)$ is negative (regardless of whether common time dummies are included). From this, it can be concluded that our results are also robust to different data sets.

\section{References}

Acemoglu, D., \& Johnson, S. (2007). Disease and development: The effect of life-expectancy on economic growth. Journal of Political Economy, 115, 925-985.

Ahituv, A. (2001). Be fruitful or multiply: On the interplay between fertility and economic development. Journal of Population Economics, 14, 51-71.

Angeles, L. (2010). Demographic transitions: Analyzing the effects of mortality on fertility. Journal of Population Economics, 23, 99-120.

Ashraf, Q., \& Galor, O. (2011). Dynamics and stagnation in the Malthusian epoch. American Economic Review, 101, 2003-2041.

Arellano, M., \& Bond, S. R. (1991). Some tests of specification for panel data: Monte Carlo evidence and an application to employment equations. Review of Economic Studies, 58, 277-297.

Baltagi, B. H., \& Griffin, J. M. (1997). Pooled estimators vs. their heterogeneous counterparts in the context of dynamic demand for gasoline. Journal of Econometrics, 77, 303-327.

Baltagi, B., \& Kao, C. (2000). Nonstationary panels, cointegration in panels, and dynamic panels: A survey. Advances in Econometrics, 15, 7-52.

Banerjee, A. (1999). Panel data unit roots and cointegration: An overview. Oxford Bulletin of Economics and Statistics, 61, 607-629.

Banerjee, A., Eberhardt, M., Reade, J.J. (2010). Panel estimation for worriers. Discussion Paper No. 514, Department of Economics, University of Oxford, Oxford.

Becker, G. S. (1965). A theory of the allocation of time. Economic Journal, 75, 493-517.

Becker, G. S., \& Lewis, H. G. (1973). On the interaction between the quantity and quality of children. Journal of Political Economy, 8, 279-288.

Blundell, R., \& Bond, S. (1998). Initial conditions and moment restrictions in dynamic panel data models. Journal of Econometrics, 87, 115-143. 
Brander, J. A., \& Dowrick, S. (1994). The role of fertility and population in economic growth. Journal of Population Economics, 7, 1-25.

Breitung, J. (2005). A parametric approach to the estimation of cointegrating vectors in panel data. Econometric Reviews, 24, 151-173.

Bun, M. J. G., \& Windmeijer, F. (2010). The weak instrument problem of the system GMM estimator in dynamic panel data models. Econometrics Journal, 13, 95-126.

Cervellati, M., Sunde, U. (2007). Human capital, mortality and fertility: A unified theory of the economic and demographic transition. IZA Discussion Paper 2905.

Cervellati, M., \& Sunde, U. (2011). Life expectancy and economic growth: The role of the demographic transition. Journal of Economic Growth, 16, 99-133.

Chambers, M. J. (2001). Cointegration and sampling frequency. Discussion Paper No. 531, Department of Economics, University of Essex.

Chambers, M. J. (2003). The asymptotic efficiency of cointegration estimators under temporal aggregation. Econometric Theory, 19, 49-77.

Cleland, J. (2001). The effects of improved survival on fertility: A reassessment. Population and Development Review, 27(Supplement), 60-92.

Doepke, M. (2004). Accounting for fertility decline during the transition to growth. Journal of Economic Growth, 9, 347-383.

Doepke, M. (2005). Child mortality and fertility decline: Does the Barro-Becker model fit the facts?. Journal of Population Economics, 18, 337-366.

Eckstein, Z., Schultz, T. P., \& Wolpin, K. I. (1984). Short-run fluctuations in fertility and mortality in pre-industrial Sweden. European Economic Review, 26, 295-317.

Eckstein, Z., Mira, P., \& Wolpin, K. (1999). A quantitative analysis of swedisch fertility dynamics. Review of Economic Dynamics, 2, 137-165.

Entorf, H. (1997). Random walks with drifts: Nonsense regression and spurious fixed-effects estimation. Journal of Econometrics, 80, 287-296.

Fisher, R. A. (1932). Statistical methods for research workers (4th ed.). Edinburgh: Oliver and Boyd.

Galloway, P. R. (1988). Basic patterns in annual variations in fertility, nuptiality, mortality, and prices in pre-industrial Europe. Population Studies, 42, 275-303.

Galor, O. (2005). From stagnation to growth: Unified growth theory. In: P. Aghion \& S. Durlauf Handbook of economic growth. Amsterdam: North-Holland.

Galor, O., \& Weil, D. N. (1996). The gender gap, fertility, and growth. American Economic Review, 86, 374-387.

Galor, O., \& Weil, D. N. (2000). Population, technology and growth: From Malthusian stagnation to the demographic transition and beyond. American Economic Review, 90, 806-828.

Galor, O., \& Moav, O. (2002). Natural selection and the origin of economic growth. Quarterly Journal of Economics, 117, 1133-1191.

Galor, O. (2011). Unified growth theory. Princeton: Princeton University Press.

Granger, C. W. J. (1990). Aggregation of time-series variables: A survey. In T. Barker \& M. H. Pesaran (Eds.), Disaggregation in econometric modelling (pp. 17-34). London: Routledge.

Granger, C. W. J., \& Newbold, P. (1974). Spurious regressions in econometrics. Journal of Econometrics, $2,111-120$.

Greenwood, J., Seshadri, A., \& Vandenbroucke, G. (2005). The baby boom and baby bust. American Economic Review, 95, 183-207.

Hakkio, C. S., \& Rush, M. (1991). Cointegration: How short is the long run?. Journal of International Money and Finance, 10, 571-581.

Hall, S. G., \& Milne, A. (1994). The relevance of p-star analysis to UK monetary policy. Economic Journal, 104, 597-604.

Hansen, B. E. (1992). Tests for parameter instability in regressions with I(1) processes. Journal of Business and Economic Statistics, 10, 321-35.

Hazan, M., \& Berdugo, B. (2002). Child labor, fertility, and economic growth. Economic Journal, 112, $810-828$.

Hendry, D. F. (1995). Dynamic econometrics. Oxford: Oxford University Press.

Herzer, D. (2008). The long-run relationship between outward FDI and domestic output: Evidence from panel data. Economics Letters, 100, 146-149.

Herzer, D., Strulik, H., Vollmer, S. (2010). The Long-run determinants of fertility: One century of demographic change 1900-1999. PGDA Working Paper No. 63, Harvard University, Cambridge.

Holly, S., Pesaran, M. H., \& Yamagata, T. (2010). A spatio-temporal model of house prices in the US. Journal of Econometrics, 158, 160-173. 
Im, K. S., Pesaran, M. H., \& Shin, Y. (2003). Testing for unit roots in heterogeneous panels. Journal of Econometrics, 115, 53-74.

Johansen, S. (1988). Statistical analysis of cointegrating vectors. Journal of Economic Dynamics and Control, 12, 231-254.

Johansen, S. (2000). Modelling of cointegration in the vector autoregressive model. Economic Modeling, 17, 359-373.

Jones, C. I. (1995). R\&D-based models of economic growth. Journal of Political Economy, 103, 759-784.

Jones, C. I. (2003). Population and ideas: A theory of endogenous growth. In P. Aghion, R. Frydman, J. Stiglitz, \& M. Woodford (Eds.), Knowledge, information and expectations in modern macroeconomics (pp. 498-521). Princeton, New Jersey: Princeton University Press.

Juselius, K. (2001). European integration and monetary transmission mechanisms: The case of Italy. Journal of Applied Econometrics, 16, 314-358.

Kalemli-Ozcan, S. (2002). Does the mortality decline promote economic growth. Journal of Economic Growth, 7, 411-439.

Kao, C. (1999). Spurious regression and residual-based tests for cointegration in panel data. Journal of Econometrics, 90, 1-44.

Kao, C., \& Chiang, M. H. (2000). On the estimation and inference of a cointegrated regression in panel data. Advances in Econometrics, 15, 179-222.

Kapetanios, G., Pesaran, M. H., \& Yamagata, T (2011). Panels with nonstationary multifactor error structures. Journal of Econometrics, 160, 326-348.

Kirk, D. (1996). Demographic transition theory. Population Studies, 50, 361-387.

Kögel, T., \& Prskawetz, A. (2001). Agricultural productivity growth and escape from the Malthusian trap. Journal of Economic Growth, 6, 337-357.

Lahiri, K., \& Mamingi, N. (1995). Power versus frequency of observation another view. Economics Letters, 49, 121-124.

Larsson, R., Lyhagen, J., \& Lthegren, M. (2001). Likelihood-based cointegration tests in heterogeneous panels. Econometrics Journal, 4, 109-142.

Lee, R., \& Anderson, M. (2002). Malthus in state space: Macro economic-demographic relations in english history, 1540 to 1840. Journal of Population Economics, 15, 195-220.

Lettau, M., \& Ludvigson, S. C. (2004). Understanding trend and cycle in asset values: Reevaluating the wealth effect on consumption. American Economic Review, 94, 276-299.

Levin, A., Lin, C. F., \& Chu, C. S. J. (2002). Unit root test in panel data: Asymptotic and finite-sample properties. Journal of Econometrics, 108, 1-24.

Lorentzen, P., Millan, J., \& Wacziarg, R. (2008). Death and development. Journal of Economic Growth, $13,81-124$.

Lütkepohl, H. (2007). General-to-specific or specific-to-general modelling? An opinion on current econometric terminology. Journal of Econometrics, 136, 319-324.

Lütkepohl, H., \& Reimers, H. E. (1992). Impulse response analysis of cointegrated systems. Journal of Economic Dynamics and Control, 16, 53-78.

Lütkepohl, H., \& Wolters, J. (1998). A money demand system for German M3. Empirical Economics, 23, 371-386.

Lütkepohl, H., \& Wolters, J. (2003). Transmission of German monetary policy in the pre-Euro period. Macroeconomic Dynamics, $7,711-733$.

Maddison, A. (2003). The world economy: Historical statistics. Paris: OECD.

Moav, O. (2005). Cheap children and the persistence of poverty. Economic Journal, 115, 88-110.

Morrisson, C., \& Murtin, F. (2009). The century of education. Journal of Human Capital, 3, 1-42.

Murtin, F. (2012). Long-term determinants of the demographic transition: 1870-2000. Review of Economics and Statistics (forthcoming).

Neher, P. A. (1971). Peasants, procreation, and pensions. American Economic Review, 61, 380-389.

Nicolini, E. (2007). Was Malthus right? A VAR analysis of economic and demographic interactions in pre-industrial England. European Review of Economic History, 11, 99-121.

Pedroni, P. (1999). Critical values for cointegration tests in heterogeneous panels with multiple regressors. Oxford Bulletin of Economics and Statistics, 61, 653-670.

Pedroni, P. (2001). Purchasing power parity tests in cointegrated panels. Review of Economics and Statistics, 83, 727-731.

Pedroni, P. (2004). Panel cointegration: Asymptotic and finite sample properties of pooled time series tests with an application to the PPP hypothesis. Econometric Theory, 20, 597-625.

Pedroni, P. (2007). Social capital, barriers to production and capital shares: Implications for the importance of parameter heterogeneity from a nonstationary panel approach. Journal of Applied Econometrics, 22, 429-451. 
Pesaran, M. H. (2006). Estimation and inference in large heterogeneous panels with a multifactor error structure. Econometrica, 74, 967-1012.

Pesaran, M. H. (2007). A simple panel unit root test in the presence of cross-section dependence. Journal of Applied Econometrics, 22, 265-312.

Pesaran, M. H., \& Shin, Y. (1998). Generalized impulse response analysis in linear multivariate models. Economics Letters, 58, 17-29.

Phillips, P. C. B, \& Hansen, B. E. (1990). Statistical inference in instrumental variables regression with I(1) processes. Review of Economic Studies, 57, 99-125.

Reher, D. S. (2004). The demographic transition revisited as a global process. Population Space and Place, 10, 19-41.

Reinsel, G. C., \& Ahn, S. K. (1992). Vector autoregressive models with unit roots and reduced rank structure: Estimation, likelihood ratio test and forecasting. Journal of Time Series Analysis, 13, 353-375.

Roodman, D. (2009). A note on the theme of too many instruments. Oxford Bulletin of Economics and Statistics, 71, 135-158.

Romer, P. M. (1990). Endogenous technological change. Journal of Political Economy, 98, S71-S102.

Sah, R. K. (1991). The effects of child mortality changes on fertility choice and parental welfare. Journal of Political Economy, 99, 582-606.

Shiller, R. J., \& Perron, P. (1985). Testing the random walk hypothesis: Power versus frequency of observation. Economics Letters, 18, 381-386.

Schultz T.P. (1997) Demand for children in low income countries. In: M. R. Rosenzweig, \& O. Stark (Eds.), Handbook of population and family economics (Vol. 1, pp. 349-430). Amsterdam: North Holland Pub. Co.

Soares, R. R (2005). Mortality reductions, educational attainment, and fertility choice. American Economic Review, 95, 580-601.

Stock, J. H., \& Watson, M. W. (1988). Testing for common trends. Journal of the American Statistical Association, 83, 1097-1107.

Stock, J. H., \& Watson, M. W. (1993). A simple estimator of cointegrating vectors in higher-order integrated systems. Econometrica, 61, 783-820.

Strulik, H. (2003). Mortality, the trade-off between child quality and quantity, and demo-economic development. Metroeconomica, 54, 499-520.

Strulik, H. (2004). Child mortality, child labour and economic development. Economic Journal, 114, 547-568.

Strulik, H. (2008). Geography, health, and the pace of demo-economic development. Journal of Development Economics, 86, 61-75.

Strulik, H., \& Weisdorf, J. (2008). Population, food, and knowledge: A simple unified growth theory. Journal of Economic Growth, 13, 169-194.

Strulik, H., Weisdorf, J. (2012). How child costs and survival shaped the industrial revolution and the demographic transition. Macroeconomic Dynamics (forthcoming).

Urbain, J. P. (1995). Partial versus full system modeling of cointegrated systems: An empirical illustration. Journal of Econometrics, 69, 177-210.

Wagner, M., \& Hlouskova, K. (2010). The performance of panel cointegration methods: Results from a large scale simulation study. Econometric Reviews, 29, 182-223.

Wang, P., Yip, C. K., \& Scotese, C. A. (1994). Fertility choice and economic growth: Theory and evidence. The Review of Economics and Statistics, 76, 255-266.

Westerlund, J. (2007). Testing for error correction in panel data. Oxford Bulletin of Economics and Statistics, 69, 709-748. 